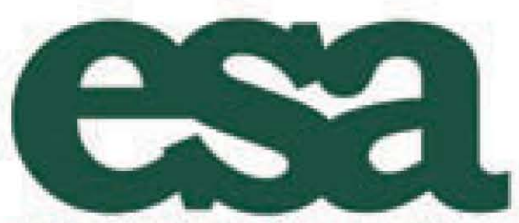

Promoting the Science of Ecology

\author{
A Simplified Forest Model to Study Species Composition Along Climate Gradients \\ Author(s): Harald K. M. Bugmann \\ Source: Ecology, Vol. 77, No. 7 (Oct., 1996), pp. 2055-2074 \\ Published by: Ecological Society of America \\ Stable URL: http://www.jstor.org/stable/2265700 \\ Accessed: 16/12/2008 07:52
}

Your use of the JSTOR archive indicates your acceptance of JSTOR's Terms and Conditions of Use, available at http://www.jstor.org/page/info/about/policies/terms.jsp. JSTOR's Terms and Conditions of Use provides, in part, that unless you have obtained prior permission, you may not download an entire issue of a journal or multiple copies of articles, and you may use content in the JSTOR archive only for your personal, non-commercial use.

Please contact the publisher regarding any further use of this work. Publisher contact information may be obtained at http://www.jstor.org/action/showPublisher?publisherCode=esa.

Each copy of any part of a JSTOR transmission must contain the same copyright notice that appears on the screen or printed page of such transmission.

JSTOR is a not-for-profit organization founded in 1995 to build trusted digital archives for scholarship. We work with the scholarly community to preserve their work and the materials they rely upon, and to build a common research platform that promotes the discovery and use of these resources. For more information about JSTOR, please contact support@ jstor.org. 


\title{
A SIMPLIFIED FOREST MODEL TO STUDY SPECIES COMPOSITION ALONG CLIMATE GRADIENTS ${ }^{1}$
}

\author{
HARALD K. M. BugmanN ${ }^{2}$ \\ Systems Ecology, Swiss Federal Institute of Technology, Zürich (ETHZ), Grabenstrasse 3, CH-8952 Schlieren, Switzerland
}

\begin{abstract}
Forest models based on the gap dynamics hypothesis ("gap models") have gained an important role in forest ecology and have grown rather complex in the last 20 yr. They have been applied extensively to study the impacts of climatic change on ecosystems although they originally were not built for this purpose.

The objectives of this study were (1) to develop a new forest gap model, ForCLIM, that includes only a minimum number of ecological assumptions but robust parameterizations of the effects of climate on plant population dynamics; (2) to test the realism of FORCLIM as compared to its predecessor model, FORECE; and (3) to examine the behavior of FORECE and FORCLIM systematically along climate gradients in Europe.

FORCLIM is composed of three modular submodels: FORCLIM-P for plant population dynamics, FORCLIM-S for soil carbon/nitrogen turnover, and FORCLIM-E for providing reliable parameterizations of the abiotic environment. For the core model, ForCLIM-P, it was found that only four factors are sufficient to model tree growth, another four factors are required to model tree establishment, and only two factors are required to model tree mortality.
\end{abstract}

The behavior of FORCLIM was tested at a large number of sites in the European Alps. The model yields tree species compositions that conform to field data and are very similar to those of the predecessor model. Based on this evaluation alone, it would not be possible to favor one of the models over the other.

The behavior of both models then was examined systematically in a parameter space spanned by the annual mean temperature and the annual precipitation sum. From this exercise it became evident that both the pattern of aboveground biomass and the realized niches of the dominating tree species are simulated realistically by ForCLIM. Extremely steep gradients are characteristic of FORECE, and many ecotones are simulated to occur in the wrong places in FORECE.

Thus, some of the current forest gap models can be simplified without reducing the realism of their behavior, and models other than FORECE should be scrutinized in this respect as well. The present study also suggests that the evaluation of model behavior at scattered sites is insufficient to show their validity for simulating forest dynamics along climate gradients. Further rigorous model comparisons and validation studies are required to increase the reliability of this promising class of models.

Key words: climatic change; Europe; FORCLIM; forest ecology; forest gap models; model comparisons; model simplification; modular modeling; niche theory; validation.

\section{INTRODUCTION}

During the past $25 \mathrm{yr}$, quantitative models of tree population dynamics based on the gap-phase dynamics hypothesis (Watt 1947) have àttracted increasing scientific attention and have produced a rich body of theory on the relative importance of the processes that shape forest succession (e.g., Bormann and Likens 1979, Shugart 1984). The adaptation of the first gap model JABOwA (Botkin et al. 1972) for southern Appalachian forests led to the model ForET (Shugart and West 1977), which successfully predicted the effect of the chestnut blight on forest composition. Subsequently

\footnotetext{
${ }^{1}$ Manuscript received 21 June 1995; revised 19 December 1995; accepted 15 January 1996; final version received 5 February 1996.

${ }^{2}$ Present address: Department of Global Change and Natural Systems, Potsdam Institute for Climate Impact Research, P.O. Box 601203, D-14412 Potsdam, Germany.
}

an amazing proliferation of forest gap models took place. Models were adapted for tropical forests in Puerto Rico (Doyle 1981), forests in Australia (Shugart and Noble 1981), in the western United States (Kercher and Axelrod 1984), in Central Europe (Kienast 1987), and in the boreal zone (Leemans and Prentice 1989, Bonan and van Cleve 1992, Shugart et al. 1992, Sirois et al. 1994). Moreover, the approach appears not to be restricted to forests: Coffin and Lauenroth (1990) successfully developed a gap model for grasslands. Thus, the gap dynamics hypothesis proved to be a viable concept in a wide variety of ecosystems.

Parallel to the adaptation of forest gap models for various ecosystems, ever more details were added to these models, such as nitrogen availability and nutrient cycling (Aber et al. 1979, Aber and Melillo 1982), the influence of fire (Kercher and Axelrod 1984), ecological indicator concepts (Kienast 1987), seed dispersal 
(Keane et al. 1990), herbaceous vegetation (Kellomäki and Väisänen 1991), and detailed biophysical-ecophysiological submodels (Bonan and van Cleve 1992, Martin 1992, Friend et al. 1993). However, the increasing complexity of forest gap models made simulation studies ever more tedious and precluded detailed model analyses. Thus, there arises the question whether the essence of the original hypothesis of forest dynamics behind these models has been cluttered by ornaments, whether all the details present in current forest gap models are necessary for producing realistic successional characteristics, and whether simpler models, i.e., models that contain less factors and require less parameters, could provide equally valid descriptions of forest dynamics. Moreover, such models would be easier to interpret ecologically and would allow for a more detailed analysis of their behavior.

Forest gap models were not developed originally for studying the influence of a changing environment on forest dynamics (Botkin et al. 1972), but their apparent success in many forest ecosystems of the world made it tempting to apply them also for projecting the future fate of forests under scenarios of global change (e.g., Shugart and Emanuel 1985, Solomon 1986, Pastor and Post 1988, Kienast 1991, Prentice et al. 1991, O'Brien et al. 1992). Undoubtedly, such applications are useful and timely. However, if forest gap models are to become more reliable tools for projecting the ecological impacts of climatic change, they must be tested rigorously to see whether they are capable of simulating the effects of a gradually changing climate on forests having a specific current structure, composition, and dynamics. A fundamental test in this respect is to determine whether these models are capable of realistically portraying the equilibrium species composition along gradients of continuously changing climatic parameters, and not only at scattered sites under current climate.

The present paper addresses these issues by focussing on Europe and the forest gap model FORECE (Kienast 1987) as a case study. The objectives of the paper are (1) to develop a new forest gap model (ForCLIM) that includes only a minimum number of ecological assumptions and robust, reliable parameterizations of the effects of climate on plant population dynamics; (2) to test the realism of ForCLIM as compared to its predecessor FORECE at the sites for which FORECE had been developed (model verification); and (3) to examine the behavior of FORECE and FORCLIM systematically along climate gradients in Europe (model validation).

\section{DESCRIPTION OF FORCLIM}

\section{Model design}

ForClim is designed as a modular model, i.e., it is composed of several independent submodels, which are assembled through defined interfaces to form a com-

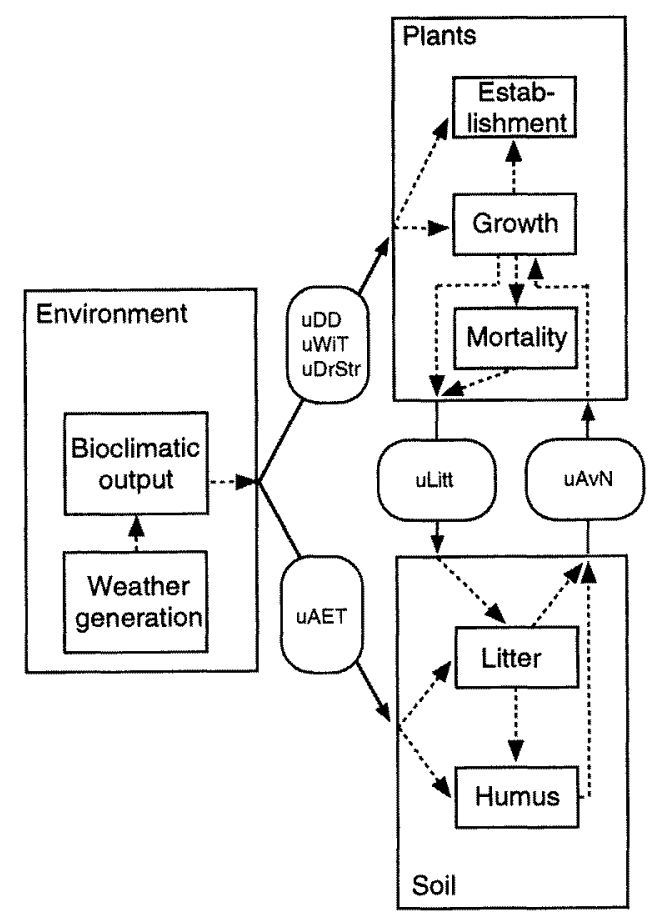

FIG. 1. Structure of the ForClim model. The variables linking the three submodels are: UWiT-parameterization of minimum actual winter temperature $\left({ }^{\circ} \mathrm{C}\right) ; \mathrm{uDD}$ - annual sum of degree-days above a $5.5^{\circ} \mathrm{C}$ threshold $\left(\mathrm{d}^{\circ} \mathrm{C}\right)$; uDrStr-annual drought stress index (-); uAET - annual actual evapotranspiration (mm/yr); uLitt-litter production (six types) $\left(\mathrm{kg} \cdot \mathrm{ha}^{-1} \cdot \mathrm{yr}^{-1}\right) ; \mathrm{uAvN}$-nitrogen availability $(\mathrm{kg} / \mathrm{ha})$.

plete forest gap model. This approach bears several advantages. The structure of the model becomes clearer, the couplings between submodels are explicit, and it is easy to exchange one submodel without affecting the others. ForClim consists of three submodels (Fig. 1):

- ForClim-E (Environment): This submodel provides time-dependent abiotic variables. It generates monthly weather data and uses them to calculate bioclimatic output variables. It does not depend on any of the other submodels and acts as an input model. Its output variables are summarized to annual indices.

- ForClim-P (Plants): The plant submodel calculates establishment, growth, and mortality of trees on a forest patch. It requires bioclimatic variables and nitrogen availability as input and calculates litter production as an output. ForCLIM-P is formulated as a discrete-time model with an annual time step.

- ForCLIM-S (Soil): The soil submodel tracks the decay of plant litter and humus in the soil as a function of bioclimatic variables. It is a discrete-time model with an annual time step and calculates the amount of nitrogen available for plant growth.

The dynamics of soil organic matter are considered explicitly for two reasons. First, such a submodel cal- 
culates the availability of soil resources as a function of weather variables, thus avoiding earlier approaches that implicitly contained climatic information (cf. Fischlin et al. 1995). Second, the explicit consideration of soil carbon dynamics makes it possible to assess the carbon balance of the whole forest ecosystem, which is important for the biospheric feedback to the climate system (Post et al. 1990). The predecessor model FORECE (Kienast 1987) does not incorporate a submodel for soil organic matter dynamics.

Forest management is disregarded in the present version of FORCLIM because the emphasis here is on the influence of climate on ecological processes. However, the modular structure of the model does not pose any obstacle to adding a submodel that simulates forest management.

In most previous forest gap models a number of individual trees of similar size are established each year (Shugart 1984). Since tree growth in these models is treated deterministically, the size of all the individuals of a given species established on a patch in a given year remains similar throughout their life-span. In FORCLIM these individuals are assumed to have identical size and are established as one tree cohort. Tree growth then may be calculated once for each cohort instead of each tree.

\section{Model formulation}

The formulation of the FORCLIM model followed as closely as possible the structure of its predecessor, FORECE (Kienast 1987). However, a quantitative analysis of the ecological factors included in FORECE was conducted to determine which factors could be omitted without reducing the realism of its simulation results (for details cf. Bugmann 1994, Bugmann and Fischlin 1994). Moreover, the remaining factors were scrutinized to see whether they contained implicit climate dependencies (Fischlin et al. 1995), and their formulation was improved accordingly. Below, an overview of FORCLIM is given; the model was documented fully by Bugmann (1994).

The following notational conventions are used: (1) The first letter of a mathematical symbol denotes its type (Swartzman and Kaluzny 1987), i.e., "u" stands for input/output variables, " $k$ " for model parameters, and " $g$ " for auxiliary variables. State variables have no prefix. (2) The subscripts " $s$ " and " $c$ " are used to denote species-specific and cohort-specific variables, respectively. Since a cohort is a subset of a species, the subscript " $c$ " implicitly contains " $s$."

\section{FORCLIM-P}

Tree growth.-As in previous models, the trees in FORCLIM are characterized by their diameter at breast height $\left(D_{c}\right)$ as a state variable. The simple carbon budget approach proposed by Moore (1989) is used to derive an equation for diameter increment. The resulting equation has a form quite similar to the conventional formulation derived by Botkin et al. (1972), but its assumptions conform more to biological expectations:

$$
\frac{\Delta D_{c}}{\Delta t}=\frac{\mathrm{k} G_{s} \cdot D_{c} \cdot\left(1-\frac{\mathrm{gH}}{\mathrm{kHm}}\right)}{274+3 \cdot \mathrm{k} B_{2, s} \cdot D_{c}+4 \cdot \mathrm{kB}_{3, s} \cdot D_{c}^{2}} \cdot f(e)_{c},
$$

where $D_{c}$ is tree diameter, $\Delta t$ is the discrete time step, $\mathrm{gH}_{c}$ is tree height, $\mathrm{kHm}_{s}$ is maximum tree height, $\mathrm{k} G_{s}$ is a growth parameter, $\mathrm{k} B_{2, s}$ and $\mathrm{k} B_{3, s}$ are allometric parameters, and $f(e)_{c}$ is a function that reduces maximum growth according to the environmental constraints described below. The derivation of Eq. 1 and an analysis of the corresponding assumptions of the Botkin et al. (1972) formulation were reviewed by Bugmann et al. (in press $b$ ).

In FORCLIM, tree height $\left(\mathrm{gH}_{c}\right)$ is calculated from tree diameter $\left(D_{c}\right)$ using the allometric relationship by Ker and Smith (1955). Leaf area and leaf mass are also predicted from tree diameter, but the allometric relationships have been improved as compared to those used by Kienast (1987) by taking into account a large set of experimental data (Burger 1945-1953). The leaves of each tree are assumed to be concentrated at the top of its stem, thus conforming to the original assumption by Botkin et al. (1972), and the penetration of light through the canopy is calculated using Beer's law.

Four factors are used to take into account suboptimal conditions for tree growth: light availability, growing season temperature, drought, and nitrogen availability (Table 1). (1) Two light response curves for shadeintolerant and shade-tolerant species are distinguished (Botkin et al. 1972), and the response curve to be used is interpolated between these two extremes by taking into account the relative shade-tolerance class of the species (Ellenberg 1986), yielding the light growth factor $\mathrm{gALGF}_{c}$. (2) For the effect of the growing season temperature on tree growth, a parabolic relationship between the annual sum of degree-days (uDD) and tree growth $\left(\mathrm{gDDGF}_{s}\right)$ is assumed (Botkin et al. 1972). (3) A square-root function (Bassett 1964) is used to relate drought stress (uDrStr) to tree growth $\left(\mathrm{gSMGF}_{s}\right)$ based on the species-specific drought tolerance, $\mathrm{kDrT}_{s}$. (4) Three asymptotic response curves (Aber et al. 1979, Pastor and Post 1985) are used to modify maximum tree growth as a function of nitrogen availability $\left(\mathrm{gSNGF}_{s}\right)$, and each species is assigned one of these response curves. This formulation does not rely on the definition of an absolute site-specific, climate-dependent maximum biomass as required in earlier models such as FORECE (cf. Fischlin et al. 1995).

To derive an overall growth reduction, these four factors must be combined. Two approaches have been used in the literature, the multiplicative one (e.g., Botkin et al. 1972), and the so-called "Liebig's Law of the minimum" (e.g., Kienast 1987). In the former case, unrealistically low growth rates are obtained when 
TABLE 1. Overview of the formulations used in the mathematical model ForCLIM-P (plant population dynamics). The reference gives the original source of the formulations; most of them were modified and improved for FoRCLIM-P.

\begin{tabular}{|c|c|c|c|}
\hline Submodel & Ecological factor & Formulation & Reference \\
\hline Tree establishment & $\begin{array}{l}\text { Minimum winter temperature } \\
\text { Light availability } \\
\text { Deer browsing } \\
\text { Temperature range }\end{array}$ & $\begin{array}{l}\text { Lowest monthly mean temperature } \\
\text { during winter (Dec, Jan, Feb) } \\
\text { Threshold of relative light intensity } \\
\text { Threshold of browsing intensity } \\
\text { Annual sum of degree-days }\end{array}$ & $\begin{array}{l}\text { Solomon (1986) } \\
\\
\text { Ellenberg (1986) } \\
\text { Kienast (1987) } \\
\text { Kienast (1987) }\end{array}$ \\
\hline Tree growth & $\begin{array}{l}\text { Maximum growth } \\
\text { Light availability } \\
\text { Growing season temperature } \\
\text { Drought } \\
\text { Nitrogen availability }\end{array}$ & $\begin{array}{l}\text { Simple carbon balance equation } \\
\text { Five functional response curves } \\
\text { Parabolic response to the annual } \\
\text { sum of degree-days } \\
\text { Square root function of the evapo- } \\
\text { transpiration deficit } \\
\text { Three functional response curves }\end{array}$ & $\begin{array}{l}\text { Moore (1989) } \\
\text { Kienast (1987) } \\
\text { Botkin et al. (1972) } \\
\text { Bassett (1964) } \\
\text { Aber et al. (1979) }\end{array}$ \\
\hline Tree mortality & $\begin{array}{l}\text { Base mortality } \\
\text { Stress-induced mortality }\end{array}$ & $\begin{array}{l}\text { Life table with constant mortality } \\
\text { Combination of absolute and rela- } \\
\text { tive thresholds of "slow } \\
\text { growth". }\end{array}$ & $\begin{array}{l}\text { Botkin et al. (1972) } \\
\text { Kienast (1987) }\end{array}$ \\
\hline Litter production & & Allometric relationships & $\begin{array}{l}\text { Pastor and Post } \\
\text { (1985) }\end{array}$ \\
\hline
\end{tabular}

many growth factors are considered, whereas the latter case is based on the unrealistic assumption that only the smallest factor limits tree growth. Ideally, the numerical value of each single factor should affect growth, not only their ranking, and growth should not converge to zero when an increasing number of nonzero factors is considered. Eq. 2, obtained following a stepwise procedure, was found to conform to the above two requirements:

$$
f(e)_{c}=\left(\mathrm{gALGF}_{c} \cdot \mathrm{gDDGF}_{s} \cdot \mathrm{gSMGF}_{s} \cdot \mathrm{gSNGF}_{s}\right)^{1 / 3} .
$$

It is acknowledged that this formulation lacks a mechanistic basis, but it yields values of $f(e)_{c}$ that are intuitively reasonable and probably superior to both the multiplicative approach and Liebig's Law. A fifth growth factor present in FORECE, the soil indicator growth factor, was omitted because it is based on synecological information (Ellenberg 1986) and should not be used for constraining the competition between trees in a forest gap model (cf. Bugmann 1994).

Tree establishment.-Following the rationale by Shugart (1984:61ff.), the processes of production, dispersal, and germination of seeds as well as the establishment and growth of seedlings are disregarded in FORCLIM. Instead, saplings are established according to four environmental filters (Table 1). (1) Sapling establishment is assumed to be impossible if the winter minimum temperature ( $\mathrm{uWiT}$ ) of the current simulation year falls below a species-specific threshold temperature $\left(\mathrm{kWiT}_{s}\right)$ (Solomon 1986). In FORECE, this was assumed to be a function of the long-term mean January temperature, which is a purely correlative approach because plants have no means of sensing the long-term mean of a climate parameter. (2) If available light at the forest floor $\left(\mathrm{gAL}_{0}\right)$ drops below a species-specific

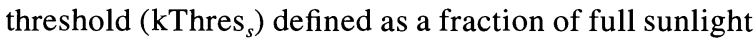
(Ellenberg 1986), sapling establishment is also pre- vented. (3) The constant browsing intensity simulated in the FORECE model (Kienast 1987) was modified to allow exploration of the possible effects of varying browsing intensities on sapling establishment rates (Bugmann 1994). (4) Sapling establishment is also assumed to be impossible when the annual sum of degreedays does not conform to the degree-day requirements of the tree species (Shugart 1984).

Establishment of saplings of a given tree species is possible if none of the above four filters applies. In this case, an overall establishment probability (kEstP) is used to determine whether establishment will take place, and the number of saplings of this species is calculated using a random number with uniform distribution in the range $[1 \ldots \mathrm{kEstNr} \cdot \mathrm{kPatchSize}]$, where $\mathrm{kEstNr}$ is the maximum sapling establishment rate (0.006 saplings $\cdot \mathrm{m}^{-2} \cdot \mathrm{yr}^{-1}$ ), and $\mathrm{kPatchSize}$ is the size of the forest patch $\left(833 \mathrm{~m}^{2}\right)$. Note that the maximum number of saplings that can be established is assumed not to be species specific.

Four establishment factors that had been incorporated in FORECE (Kienast 1987) turned out to have a negligible influence on the simulated forest dynamics in Europe, i.e., the temperature indicator concept, the occurrence of spring frosts, the influence of local seed production, and sprouting from stumps. Based on an evaluation of the ecological significance of these factors in the context of long-term forest dynamics (Bugmann 1994), it was decided to omit them for the derivation of FORCLIM.

Tree mortality. - In ForCLIM-P the establishment and growth of tree cohorts are modeled. However, the mortality functions are evaluated for each member of each tree cohort individually. There are two sources of mortality in FORECE and in ForCLIM (Table 1). (1) The base mortality is calculated as a Poisson process by assuming that the annual tree mortality rate $\left(\mathrm{g} P_{m 1, s}\right)$ 
TABLE 2. Overview of the formulations used in the mathematical model ForCLIM-S (submodel for the turnover of soil organic matter). The reference gives the original source of the formulations; most of them were modified and improved for FORCLIM-S (for details, see Bugmann 1994).

\begin{tabular}{|c|c|c|c|}
\hline Submodel & Process & Formulation & Reference \\
\hline \multirow[t]{4}{*}{ Litter decay } & Mass loss & Empirical function of lignin: $\mathrm{N}$ rato & Pastor and Post (1985) \\
\hline & Nitrogen immobilization & $\begin{array}{l}\text { Empirical function of mass loss, im- } \\
\text { proved not to violate the nitrogen } \\
\text { balance }\end{array}$ & Melillo et al. (1982) \\
\hline & Nitrogen leaching & Empirical function of nitrogen content & Cole and Rapp (1981) \\
\hline & Weather constraint & $\begin{array}{l}\text { Actual evapotranspiration (regression } \\
\text { function) }\end{array}$ & Meentemeyer (1978) \\
\hline \multirow[t]{3}{*}{ Humus decay } & Mass loss & $\begin{array}{l}\text { Fixed C: } N \text { ratio of humus, mass loss } \\
\text { proportional to nitrogen turnover }\end{array}$ & Pastor and Post (1985) \\
\hline & Nitrogen mineralization & $\begin{array}{l}\text { Empirical relationship, improved for } \\
\text { wide range of applicability }\end{array}$ & Pastor et al. (1984) \\
\hline & Weather constraint & Actual evapotranspiration (multiplier) & Pastor and Post (1985) \\
\hline
\end{tabular}

is constant throughout tree life, which corresponds to the negative exponential curve for survivorship. The function $\mathrm{g} P_{m 1, s}$ is scaled so that $1 \%$ of the trees reach the age specified by the species-specific parameter $\mathrm{kAm}_{s}$ (Shugart 1984). (2) The stress-induced mortality rate $\left(\mathrm{g} P_{m 2, c}\right)$ applies when a tree's diameter has increased $<10 \%$ of the maximum diameter increment (Eq. 1) or $<0.3 \mathrm{~mm}$ for $\geq 2 \mathrm{yr}$. It is scaled so that only $1 \%$ of the trees would survive for $10 \mathrm{yr}$ if they were subject to this mortality rate alone (Solomon 1986).

Eq. 3 describes the calculation of the overall mortality probability for each member of a tree cohort and each year $\left(\mathrm{g} P_{m, c}\right)$ :

$$
\mathrm{g} P_{m, c}=\mathrm{g} P_{m 1, s}+\left[1-\mathrm{g} P_{m 1, s}\right] \cdot \mathrm{g} P_{m 2, c}
$$

Two things about the stress-induced mortality rate deserve to be emphasized here. First, it provides the link between tree growth and tree mortality in forest gap models. Second, it introduces a second state variable per tree cohort in the model, namely the number of years a tree has grown "slowly" $\left(\mathrm{SGr}_{c}\right)$, i.e., slower than the two thresholds. Hence, each tree cohort in FORCLIM is characterized by two state variables: its diameter $\left(D_{c}\right)$ and the number of "slow-growth" years $\left(\mathrm{SGr}_{c}\right)$.

\section{FORCLIM-S}

The formulation of FORCLIM-S is very similar to the soil submodel of LiNKAGES (Pastor and Post 1985). LINKAGES was chosen because it is one of the few carbon cycle models for forests that treats explicitly the effects of both climatic parameters and substrate chemistry on decomposition rates. Moreover, this model was used successfully in many subsequent studies (Pastor and Post 1986, 1988, Shugart and Urban 1989, Martin 1992, Pastor and Naiman 1992).

The litter produced by the trees in a given year loses carbon continuously during decomposition, but the rate of nitrogen uptake by the microbes attacking the tissue is initially greater than the release of nitrogen from the tissue; this results in a net immobilization of nitrogen (e.g., Berg and Staaf 1981, Waring and Schlesinger 1985). Thus, in ForClim-S two state variables are used to characterize litter: its organic matter content $\left(\mathrm{LOM}_{c}\right)$, and its nitrogen content $\left(\mathrm{LN}_{c}\right)$. The litter becomes progressively richer in recalcitrant compounds, and the rate of nitrogen release begins to exceed the uptake, leading to nitrogen mineralization. Pastor and Post (1985) call the material in this stage "humus." The change from immobilization to mineralization, and thus the transition from "litter" to "humus," generally occurs at nitrogen concentrations of $\approx 2 \%$ of mass (Alexander 1977). Similar to the litter, the humus is characterized by its organic matter (HOM) and nitrogen content (HN).

The basic idea behind the decomposition module in LINKAGES and thus FORCLIM-S is to formulate the decay rates based on the wealth of data obtained from litterbag studies (e.g., Meentemeyer 1978, Melillo et al. 1982, Pastor et al. 1984). To this end, the decay of each year's litter is tracked through time, thus mimicking many litterbag studies. When the critical nitrogen concentration (Alexander 1977) is reached, the litter is transferred to a common "humus" compartment, and nitrogen mineralization starts. The amount of nitrogen available for plant growth $(\mathrm{uAvN})$ is calculated as the difference between the nitrogen mineralized from the humus pool and the immobilization demand of the litter cohorts (Table 2).

Unfortunately, most of the litterbag studies to date were conducted under boreal conditions and/or in America; only few data are available for central European conditions and species (e.g., Berg and Staaf 1981, Ellenberg 1986). Thus it was necessary to aggregate the 17 litter types distinguished in LINKAGES to three types of leaf litter (fast, medium, and slow decay), twig litter, root litter, and stemwood litter.

\section{FORCLIM-E}

The submodel ForCLIM-E has two tasks: (1) to provide weather data based on long-term climatic data, and (2) to provide the bioclimatic input data required by the other submodels, i.e., winter minimum temper- 
TABLE 3. Overview of the formulations used in the mathematical model ForCLIM-E (environment submodel).

\begin{tabular}{|c|c|c|c|}
\hline Submodel & Variable & Formulation & Reference \\
\hline Weather generator & $\begin{array}{l}\text { Monthly means of temperature } \\
\text { and precipitation }\end{array}$ & $\begin{array}{l}\text { Drawn stochastically from long-term } \\
\text { distributions by taking into account } \\
\text { the cross-correlation between the } \\
\text { variables }\end{array}$ & original $\uparrow$ \\
\hline \multirow[t]{4}{*}{ Bioclimatics } & Growing season temperature & $\begin{array}{l}\text { Unbiased estimation of the annual de- } \\
\text { gree-day sum based on monthly } \\
\text { mean temperature }\end{array}$ & original \\
\hline & Minimum winter temperature & $\begin{array}{l}\text { Minimum of monthly mean tempera- } \\
\text { tures of winter months (Dee, Jan, } \\
\text { Feb) }\end{array}$ & $\begin{array}{l}\text { Fischlin et al. } \\
\text { (1995) }\end{array}$ \\
\hline & Drought & $\begin{array}{l}\text { Evapotranspiration deficit based on a } \\
\text { bucket model of soil moisture bal- } \\
\text { ance modified to contain no implic- } \\
\text { it climate dependencies }\end{array}$ & $\begin{array}{l}\text { Fischlin et al. } \\
\text { (1995) }\end{array}$ \\
\hline & Evapotranspiration & Same bucket models as above & $\begin{array}{l}\text { Fischlin et al. } \\
\text { (1995) }\end{array}$ \\
\hline
\end{tabular}

† Developed in collaboration with Dimitrios Gyalistras, Swiss Federal Institute of Technology Zürich.

ature (uWiT), the annual sum of degree-days (uDD), actual evapotranspiration (uAET), and drought stress (uDrStr; Fig. 1). These could be calculated best from detailed weather records, e.g., hourly measurements. However, within an ecosystem model that calculates forest succession over many centuries, such a resolution is hardly feasible (cf. Bonan and van Cleve 1992, Bonan 1993, Bugmann and Martin 1995). Thus, as a consequence the precision of detailed weather data is sacrificed to allow for general and simple calculations of the abiotic conditions. Monthly weather data are used in FORCLIM-E because they capture the annual weather cycle and mediate between the annual time step of the other submodels and more detailed approaches (Table 3 ).

Generation of weather data. - In FORCLIM, the calculation of bioclimatic indices depends on temperature and precipitation data only. The monthly means of temperature $\left(T_{m}\right)$ and precipitation $\left(P_{m}\right)$ are sampled stochastically from their respective long-term statistics. Lacking more precise and at the same time general models for the distribution of the variables, it is assumed that both variables are distributed normally around their long-term means (cf. Fliri 1974). In most previous gap models including FORECE, monthly temperature and precipitation data were sampled independently, although the cross-correlation between the variables is not negligible (cf. Bugmann 1994). For this reason, the cross-correlation is taken into account in the weather generator used in For CLIM-E (Table 3).

Calculation of bioclimatic output variables.--In FORECE, it was assumed that winter minimum temperature ( $\mathrm{WWiT}$ ) could be parameterized as the long-term mean temperature of January. This static approach was replaced in FORCLIM-E by calculating UWiT as the minimum of the actual mean monthly temperatures of the winter months December, January, and February. Prentice et al. (1992) showed that the monthly mean temperature is closely correlated with the absolute min- imum temperature, so that the monthly mean temperature can be used to parameterize the effects of minimum temperature in a model of long-term successional processes such as FORCLIM.

The concept of degree-days, i.e., a linear dependency of the growth rate on temperature above a threshold, was used in most forest gap models developed to date (Shugart 1984). The tree species native to the European Alps have rather similar threshold temperatures of net photosynthesis (Lyr et al. 1992). It is therefore justifiable to use a threshold temperature that is independent of the single tree species. By doing so, the annual sum of degree-days becomes an abiotic index of the forest environment.

The classical approach to calculating the annual sum of degree-days in forest gap models is (Botkin et al. 1972, Kienast 1987):

$$
\mathrm{uDD}=\sum_{m=1 \mathrm{Ian}}^{\mathrm{Dec}} \operatorname{MAX}\left(T_{m}-\mathrm{kDTT}, 0\right) \cdot \mathrm{kDays}_{m},
$$

where $\mathrm{kDTT}$ is the threshold temperature of net photosynthesis, and $\mathrm{kDays}_{m}$ is the number of days of month $m$. Unfortunately, this approximation is subject to a site-specific bias, which may influence the simulated species composition (Fischlin et al. 1995). Hence, for ForCLIM-E an empirical correction function was developed to account for this bias (Eq. 5). The improved method is still based on monthly mean temperatures only, but it provides an accurate approximation of more detailed methods of degree-day estimation, such as Allen's (1976) method, which is based on daily minimum and maximum temperatures:

$$
\begin{aligned}
\mathrm{uDD}=\sum_{m=\mathrm{Jan}}^{\mathrm{Dec}} & {\left[\operatorname{MAX}\left(T_{m}-\mathrm{kDTT}, 0\right) \cdot \mathrm{kDays}\right.} \\
& \left.+\operatorname{gCorr}\left(T_{m}\right)\right]
\end{aligned}
$$

where gCorr is the empirical correction function. For 
a full description of the development of this equation cf. Bugmann (1994).

For calculating evapotranspiration and drought, a model of soil moisture content is required. The "bucket" model by Thornthwaite and Mather (1957), although an entirely empirical approach, is especially useful because it is based on monthly mean temperatures and monthly precipitation sums only, and it appears to provide a reasonable estimate of potential and actual evapotranspiration for temperate latitudes. Correspondingly, it was used in many empirical and modeling studies (e.g., Müller 1982, Meentemeyer et al. 1985, Mintz and Serafini 1992) as well as in most forest gap models (e.g., Pastor and Post 1985, Solomon 1986, Kienast 1987). In FORCLIM, this approach is used as well.

However, three modifications were made to the Thornthwaite and Mather (1957) model:

- It is a standard practice in forest gap models to reset soil moisture to field capacity at the beginning of each simulation year (cf. Bugmann and Martin 1995, Fischlin et al. 1995), which means that under many climatic conditions additional precipitation is introduced in the model; this constraint was relaxed by using the soil moisture of the previous December as the initial condition for the new simulation year.

- Slope and aspect of the terrain can have a considerable effect on the amount of incident radiation (e.g., Running et al. 1987), which influences potential evapotranspiration $\left(\mathrm{PET}_{m}\right)$. Thus, $\mathrm{PET}_{m}$ as calculated in FORECE is modified by a multiplicative parameter in FORCLIM to take into account the slope and aspect of the site.

- Most previous gap models used the number of days where soil moisture is below the permanent wilting point to parameterize the occurrence of drought stress. Fischlin et al. (1995) showed that this approach is ill defined and leads to artefacts in the model behavior. As a more physiology-based index, the evapotranspiration deficit (Eq. 6) is used to parameterize drought occurrence in FORCLIM-E:

$$
\mathrm{uDrStr}=1-\frac{\mathrm{uAET}}{\mathrm{uPET}},
$$

where uPET and uAET are the annual sums of potential and actual evapotranspiration, respectively.

\section{Parameter estimation}

Most of the parameters required by ForCLIM were estimated from a large body of literature data; the details may be found in Bugmann (1994). ForCLIM-P was parameterized to include 30 tree species of Europe (Hess et al. 1980, Kienast 1987), and it was tried to obtain an estimate of each of the $14 \times 30=420$ species-specific model parameters that was independent of previous modeling efforts. The climatic data for all the study sites were obtained from the Swiss Meteorological Agency (Bantle 1989, SMA 1901-1990).

\section{Model implementation}

FORCLIM was implemented using the modeling and simulation software RAMSES (Fischlin 1991). RAMSES allows modular modeling, i.e., to split complex (ecosystem) models into several submodels, and supports the coupling of models with different model formalisms. RAMSES is based on the DialogMachine (Fischlin et al. 1987), which provides an open and flexible user interface, and on the high-level programing language Modula-2 (Wirth 1985, Wirth et al. 1992). The simulation session of RAMSES is based on the simulation environment ModelWorks (Fischlin et al. 1994); it offers both interactive and batch-oriented simulations as well as full access to the DialogMachine and Modula2 , providing the flexibility for programing additional routines, e.g., for the statistical analysis of simulation results at runtime of the model. The model runs in the interactive and in the batch mode on Apple Macintosh computers. A full version for the IBM-PC/Windows is in preparation. On SUN and IBM work stations, FORCLIM runs in the batch mode under the software RASS (Thöny et al. 1994).

\section{DEsign OF Simulation EXPERIMENTS \\ Model verification}

The successional properties as simulated by the FORECE and FORCLIM models were evaluated at a large number of sites in the Swiss part of the European Alps (subalpine zone-Bever, Cleuson, Davos, Zermatt; montane zone-Airolo, Adelboden, Montana; colline zone-Huttwil, Bern, Schaffhausen, Basel, Sion), covering a range of environmental conditions that extend from the cold timberline at the highest elevations (Cleuson) to the dry timberline in central alpine valleys (Sion).

The site-specific parameters for the models, such as the field capacity, the permanent wilting point of the soil and, for FORECE, the value of maximum aboveground biomass (parameter SOILQ) were taken from the simulation studies by Kienast $(1987,1991)$ and Kienast and Kuhn $(1989 a, b)$. FORCLIM was run in a setup that is closest to the structure of FORECE, i.e., by using only the model combination FORCLIM-E/P. In this setup, nitrogen availability is constant (Fig. 1) and must be specified as a parameter. At all sites, a nutrientrich soil with a nitrogen availability of $100 \mathrm{~kg} / \mathrm{ha}$ was assumed for FORCLIM-E/P.

At all sites, the transient behavior of the models was studied for 1200 simulation years starting from a bare patch. For ForCliM, the simulation results from 200 independent patches were averaged to obtain the behavior at the ecosystem level (cf. Bugmann and Fischlin 1992, Bugmann et al., in press a). Only 50 patches per site were simulated with the FORECE model due to implementation restrictions (Kienast 1987). 


\section{Model validation}

Rehder (1965) and Ellenberg (1986) synthesized a vast amount of phytosociological data into a hypothesis on the dominating species of unmanaged forests in central Europe, i.e., the realized niches of these species (see Fig. 3). This scheme represents a "Clementsian" climax view of forests in the climate space (Clements 1936), resulting after a long directional succession under stable environmental conditions. Forest gap models, on the other hand, are based on the "Gleasonian" view of vegetation succession (Gleason 1939), emphasizing cyclic vegetation change under changing environmental conditions on small patches of land. However, at the level of the forest ecosystem, i.e., across many patches, forest gap models also produce a stable "climax" state (cf. Fig. 2). Therefore, the climax states of classical phytosociology and the steady states of gap model simulations can be compared in a straightforward manner, although they are based on a different theory of vegetation dynamics.

Usually, comparisons of field data with model results are possible on a site-by-site basis only. One attractive aspect of the environmental space presented by Rehder (1965) and Ellenberg (1986) -is that it overcomes this limitation by putting a large number of point-oriented phytosociological relevés into a gradient perspective. Therefore I decided to test the behavior of the three models FORECE, FORCLIM-E/P, and the full FORCLIM$\mathrm{E} / \mathrm{P} / \mathrm{S}$, by systematically simulating the equilibrium species composition in this climate space (Fig. 3). It should be noted that the borders within Fig. 3 separate climate zones, not necessarily vegetation zones. However, one may expect that the transitions between the vegetation zones given in Fig. 3 occur gradually near the boundaries between the climate zones.

For this simulation study the annual cycles of temperature and precipitation had to be reconstructed based only on the annual means (Fig. 3). To this end, the monthly climate data from 12 sites in the Alps (Bugmann 1994) were analyzed for their annual cycles, and it was found that the monthly mean temperature and the monthly precipitation sum at any of the stations could be predicted excellently by differences (temperature) and fractions (precipitation) with respect to the annual values. The standard deviations of temperature and precipitation were found to be more variable (Bugmann 1994). The average monthly standard deviation of each variable from all 12 sites was used for the simulation in the whole climate space.

The temperature amplitude (i.e., the difference between long-term July and January temperature) increases slightly in drier climates, and this is the reason why the alpine timberline in Fig. 3 is found at lower annual mean temperatures as precipitation decreases. This was accounted for by modifying the temperature amplitude as a linear function of the annual precipi- tation sum. For details of this derivation, see Bugmann (1994).

In the simulations, the annual mean temperature was varied from $-2^{\circ}$ to $13^{\circ} \mathrm{C}$, and one simulation experiment was performed every $0.5^{\circ} \mathrm{C}$. The annual precipitation sum was varied from 400 to $2000 \mathrm{~mm} / \mathrm{yr}$, with one experiment every $100 \mathrm{~mm} / \mathrm{yr}$. For each of these 527 points in the $(T, P)$ space, the equilibrium species composition was estimated using a new, efficient method that averages the simulation results across 200 points in time and not across many patches, thus reducing the required simulation time by $87 \%$. The method is based on the fact that the stochastic process simulated by forest gap models appears to be stationary, i.e., that the average over many simulation runs is the same as the average over time of one single run (for a detailed description of the method, cf. Bugmann 1994).

Lacking precise data on soil properties as a function of climate, field capacity was assumed to be $30 \mathrm{~cm}$ throughout the $(T, P)$ space and in all models, and for the model variant FORCLIM-E/P available nitrogen was assumed to be $100 \mathrm{~kg} / \mathrm{ha}$ throughout the $(T, P)$ space. For FORECE, the additional site parameters were adapted from Kienast (1987). The simulation studies with the FORCLIM models were executed on Macintosh computers. Because simulation studies with FORECE require much more computing time, they had to be performed on a Sun SS630 workstation and still took $>3 \mathrm{wk}$.

\section{RESULTS}

\section{Model verification}

The simulation results at all sites along the environmental gradient in the Alps were qualitatively similar between the two models. Three typical examples are shown in Fig. 2.

Site Bever.-For a south-facing slope at the site Bever, FORCLIM-E/P predicts a forest dominated by larch (Larix decidua) in the early phase and Swiss Stone pine (Pinus cembra) in the late successional phase (plant nomenclature follows Hess et al. 1980). When a northfacing slope is simulated with FORCLIM-E/P, a larchNorway spruce (Picea excelsa) forest is produced (data not shown). FORECE lacks a differentiation between sites of different slope and aspect; at Bever it yields a species composition that is very similar to the one from FORCLIM-E/P for south-facing slopes.

There is one systematic deviation between the two models across all sites: FORECE predicts consistently lower biomass than FORCLIM (Fig. 2). At the site Bever, the simulated aboveground biomass in the equilibrium is slightly below $200 \mathrm{t} / \mathrm{ha}$, whereas in FORCLIM-E/P it reaches slightly $>300 \mathrm{t} / \mathrm{ha}$.

Site Davos.-Again, both models agree to a large extent as to the type of forest (Fig. 2), yielding a large share of $L$. decidua in the early-successional phase and a dominance of $P$. excels $a$ in the steady state. There 

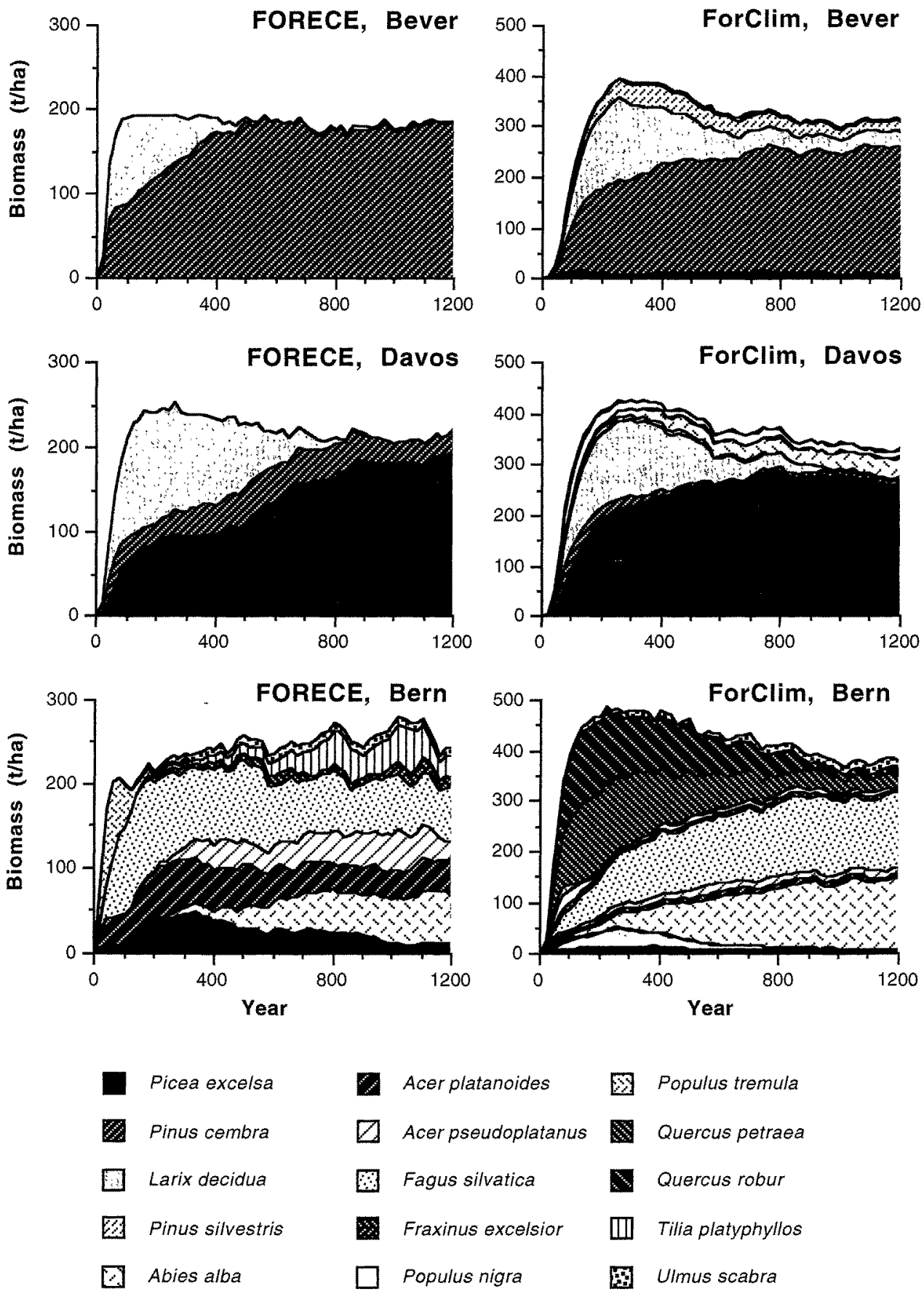

FIG. 2. Simulation results from FORECE (left) and FORCLIM-E/P (right) at the three test sites: Bever (top; south-facing slope), Davos (center), and Bern (bottom). The panels show the average cumulative species-specific biomass starting from a bare patch in the simulation year 0 . For the location of the test sites in the climate space, see Fig. 3.

are some minor differences concerning the biomass of $P$. cembra and the presence of Abies alba and Populus nigra, both of which are absent in FORECE but have a minor role in ForCLIM.

The equilibrium aboveground biomass in both models increases slightly compared to the site Bever: FO-
RECE yields $\approx 220 \mathrm{t} / \mathrm{ha}$, whereas ForCLIM-E/P lies at almost $350 \mathrm{t} / \mathrm{ha}$.

Site Bern.-At first sight, the two models appear to produce strong differences as to the simulated equilibrium species composition at Bern (Fig. 2). However, they agree that the most abundant late-successional 


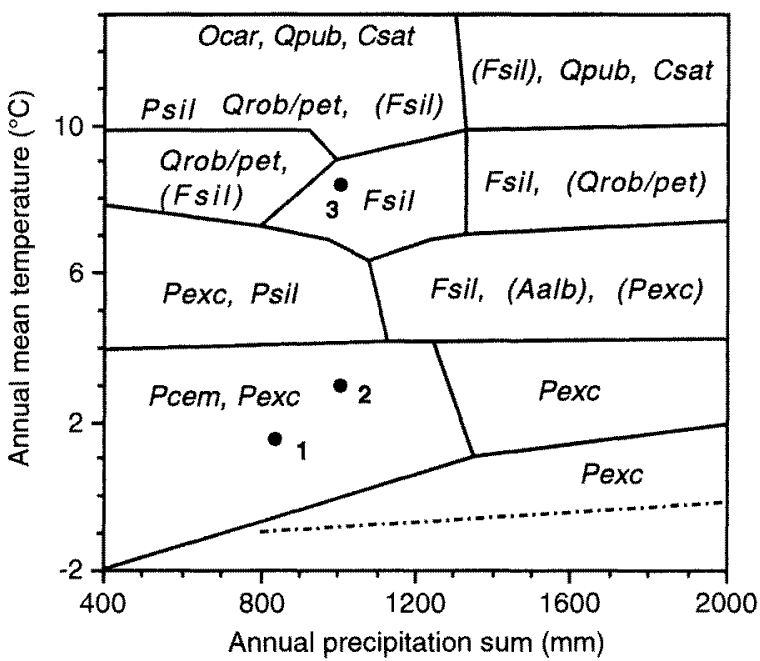

FIG. 3. Dominating tree species in a space spanned by the annual precipitation sum and the annual mean temperature according to Rehder (1965) and Ellenberg (1986). Key to species: Aalb-Abies alba; Csat-Castanea sativa; Fsil-Fagus silvatica; Ocar-Ostrya carpinifolia; Pcem-Pinus cembra; Pexc-Picea excelsa; Psil-Pinus silvestris; QpetQuercus petraea: Qpub-Quercus pubescens; Qrob-Quercus robur. The dash-dotted line close to the bottom of the graph indicates the approximate location of the alpine timberline. The numbered dots indicate the location of the test sites of Fig. $2(1=$ Bever, $2=$ Davos, $3=$ Bern $)$.

species is Fagus silvatica, followed by A. alba. In FORECE, also Acer platanoides and Tilia platyphyllos reach large biomass. Both models simulate the presence of a large number of other deciduous species at low abundance.

In the early-successional phase, however, there is stronger disagreement between the two models (Fig. 2 ), concerning mainly the presence of oak (Quercus spp.), which is absent completely in FORECE but has a considerable share in FORCLIM.

The simulated total aboveground biomass in the equilibrium raises to almost $250 \mathrm{t} / \mathrm{ha}$ in FORECE and to $400 \mathrm{t} / \mathrm{ha}$ in For ClIM.

\section{Model validation}

It is beyond the scope of this paper to discuss the simulated realized niches of all the 30 tree species that are included in the three gap models FORECE, ForCLIM-E/P, and ForCLIM-E/P/S. Below, the pattern of simulated total aboveground biomass will be presented as an indicator of forest productivity and carbon storage, and the realized niches of three species that are most characteristic of typical communities throughout the climate space will be shown, i.e., Norway spruce ( $P$. excelsa), Swiss Stone pine ( $P$. cembra), and European beech $(F$. silvatica). Finally, the ecotones simulated by the three models will be evaluated. In the following, the symbols " $T$ " and " $P$ " are used denote the annual mean temperature and the annual precipitation sum, respectively.
Aboveground carbon storage.-There is one qualitative difference between FORECE and FORCLIM simulations regarding total aboveground biomass (Fig. 4): FORECE yields the largest biomass values (up to 500 $\mathrm{t} / \mathrm{ha}$ ) close to the alpine timberline and a sharp drop of the biomass around $T=3^{\circ} \mathrm{C}$. When temperature increases further, the biomass remains almost constant at $\approx 250 \mathrm{t} / \mathrm{ha}$. ForCLIM, on the other hand, produces continuously increasing values of aboveground biomass from $<200 t /$ ha near the alpine timberline to 400 t/ha (ForCLIM-E/P) and 450 t/ha (FORCLIM-E/P/S).

On the other hand, both models agree that for any fixed annual mean temperature there is hardly any change of the aboveground biomass for a wide range of precipitation as long as $P>750 \mathrm{~mm} / \mathrm{yr}$ (FORECE) or $P>1000 \mathrm{~mm} / \mathrm{yr}$ (ForCLIM) (Fig. 4), followed by a rather sharp drop as precipitation decreases further towards the dry timberline.

There is a systematic difference in the pattern of aboveground biomass between the two ForCLIM variants. In ForCLIM-E/P/S total biomass increases above the level reached by ForCLIM-E/P because at higher annual mean temperatures, nitrogen availability in FORCLIM-E/P/S exceeds the value of $100 \mathrm{~kg} / \mathrm{ha}$ prescribed for FORCLIM-E/P, thus allowing higher productivity and aboveground carbon storage (Fig. 4).

Realized niches of dominating species.-When comparing the distribution of the dominating tree species from Fig. 3 with the simulated realized niches of these species (Figs. 5-7), it becomes evident that ForCLIM and FORECE differ qualitatively with respect to the steepness of the biomass decline as one approaches the distribution limits of most species:

1. Picea excelsa.-In FORECE, $P$. excelsa is excluded abruptly from the area where $T<2^{\circ} \mathrm{C}$ (Fig. 5), and there is a similarly steep gradient of its biomass when approaching $5^{\circ} \mathrm{C}$. In both ForCLIM variants, the species grows up to the alpine timberline (Fig. 5) and decreases more smoothly towards higher temperatures. The three models agree that $P$. excelsa does not grow where precipitation drops below $800 \mathrm{~mm} / \mathrm{yr}$. The major difference between the results of FORCLIM-E/P and FORCLIM-E/P/S is that the biomass of $P$. excelsa is reduced to some extent when nitrogen availability is simulated explicitly with ForCLIM-S (Fig. 5). Although average nitrogen availability is higher, ForCLIM-S simulates extended periods where the immobilization of nitrogen predominates and nitrogen availability drops to low values, which is a competitive drawback for $P$. excelsa.

2. Pinus cembra.-Both models agree that $P$. cembra is a subalpine species that does not occur above $T$ $=4^{\circ} \mathrm{C}$. FORECE suggests that $P$. cembra dominates under all precipitation regimes when $T$ is $<2^{\circ} \mathrm{C}$ (Fig. 6). With both ForClim variants, $P$. cembra is abundant only in the dry (continental) subalpine zone, and it is codominant close to the alpine timberline in the other areas (Fig. 6). 

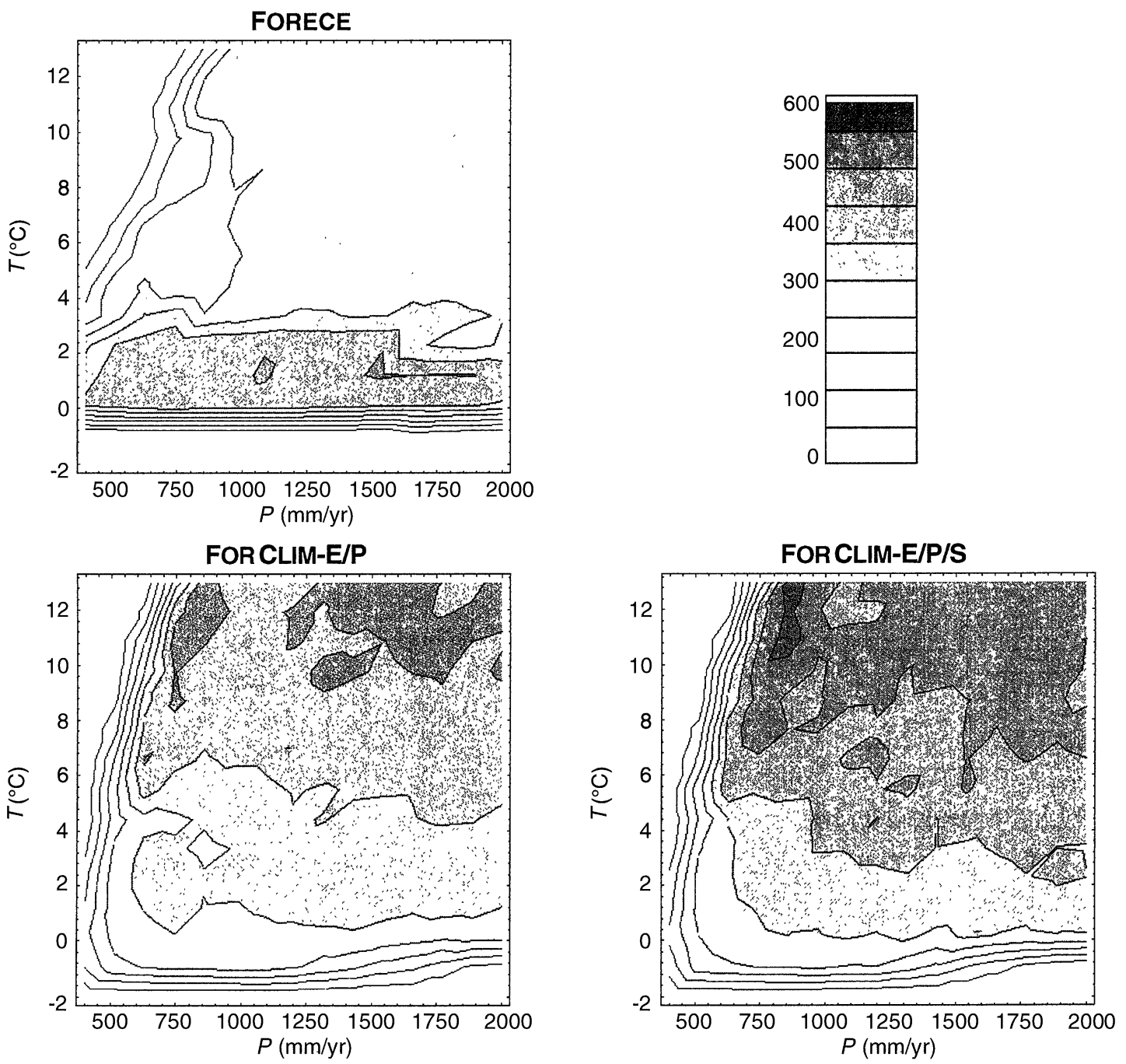

FIG. 4. Total aboveground biomass ( $\mathrm{t} / \mathrm{ha}$ ) as simulated by the three models (FORECE, FORCLIM-E/P, and FORCLIM-E/P/S) in a space spanned by the annual precipitation sum $(P)$ and the annual mean temperature $(T)$.

3. Fagus silvatica.- - Similar steep gradients as observed with $P$. excelsa and $P$. cembra occur along the temperature axis with $F$. silvatica in FORECE (Fig. 7). There is an abrupt decline at $T \approx 5^{\circ} \mathrm{C}$, whereas FORCLIM yields a smoother gradient, and the species extends to slightly lower temperatures than in FORECE. However, both models agree that there is a sharp decline of $F$. silvatica as climate gets drier, but the species extends to drier conditions (lower precipitation) in FORCLIM than in FORECE.

Ecotones.-The following ecotones will be presented and discussed in turn: (1) the location of the timberlines; (2) the gradient of communities under moist conditions $(P>1000 \mathrm{~mm})$ from the alpine timberline to $T \approx 10^{\circ} \mathrm{C}$ (model response to temperature); (3) the gradient of communities along decreasing precipitation (model response to drought).

1. Location of the timberlines.-All three models agree that the dry timberline follows roughly a straight line in the $(T, P)$ space, extending from the point $\left[13^{\circ} \mathrm{C}\right.$, $700 \mathrm{~mm} / \mathrm{yr}]$ down to about $\left[5^{\circ} \mathrm{C}, 400 \mathrm{~mm} / \mathrm{yr}\right]$ (Fig. 4). In FORECE, the alpine timberline is located at $T \approx$ $-0.5^{\circ} \mathrm{C}$, and the slope of the timberline in Fig. 4 is slightly negative (i.e., the timberline occurs at higher temperatures when precipitation is low, and vice versa). In FORCLIM, the timberline does not follow a straight line, but it is located at $T \approx-0.5^{\circ} \mathrm{C}$ when $P=2000$ $\mathrm{mm} / \mathrm{yr}$ and decreases to around $T \approx-1.5^{\circ} \mathrm{C}$ when $P$ $=500 \mathrm{~mm} / \mathrm{yr}$, i.e., in contrast to FORECE its slope is positive.

2. Model response to temperature gradient.-All three models simulate the transition from the subalpine coniferous to mixed deciduous forests at lower elevations, as evidenced by the sequence of the dominating species ( $P$. cembra-P. excelsa-F. silvatica). However, FORECE and FORCLIM diverge to a large extent concerning the distribution of single species (Figs. 5-7). FORECE simulates the ecotones between 

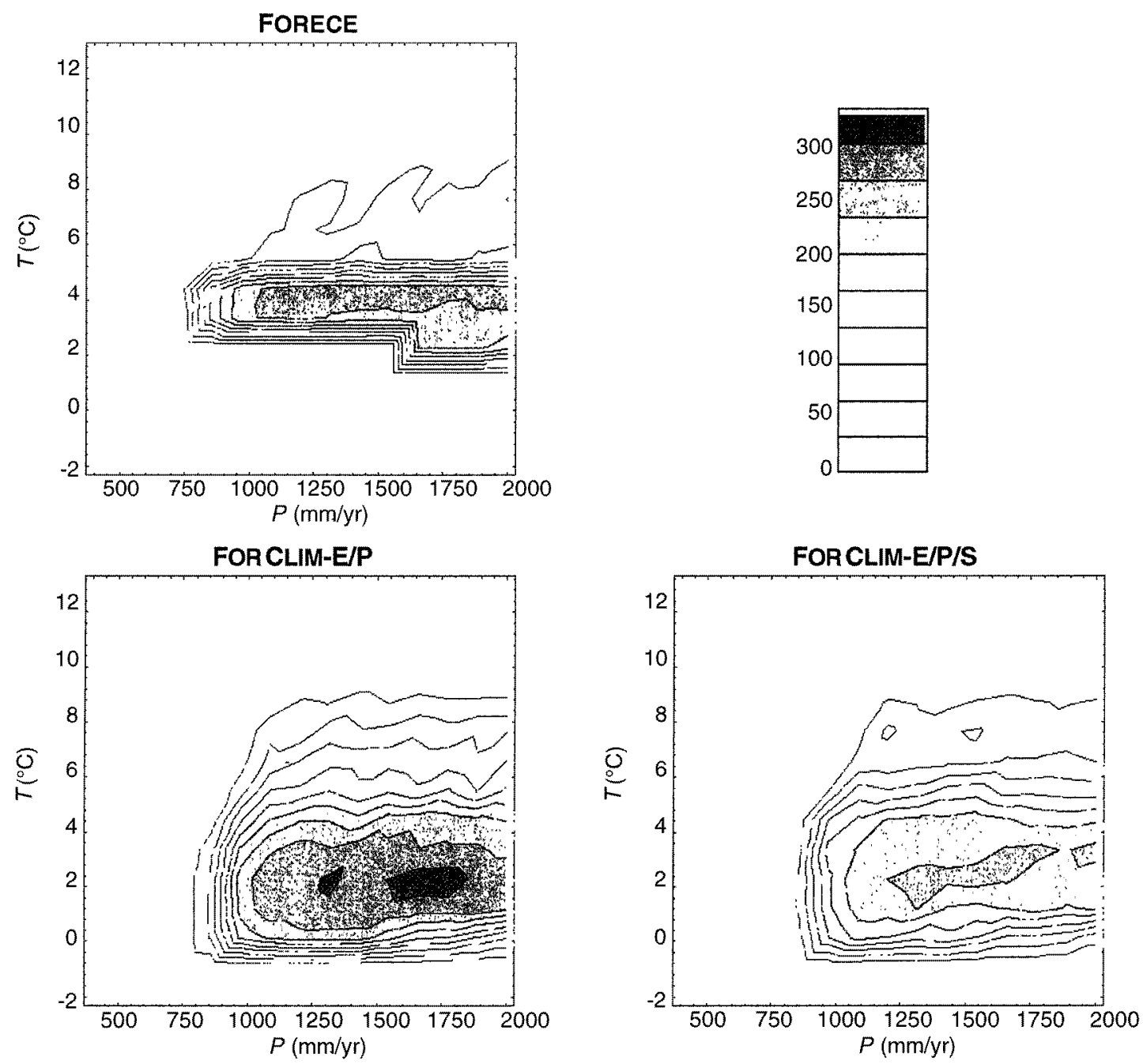

FIG. 5. Contour plot of Picea excelsa biomass ( $\mathrm{t} / \mathrm{ha}$ ) as simulated by FORECE (top), ForCLIM-E/P (bottom left), and ForCLIM-E/P/S (bottom right).

the dominating species in other places than FORCLIM, and the FORECE ecotones often do not conform to phytosociological data (Fig. 3). On the other hand, both FORCLIM variants produce a plausible gradient of species composition from the alpine timberline up to $\approx 10^{\circ} \mathrm{C}$. A small belt of $P$. cembra close to the timberline (Fig. 6) is followed by the subalpine spruce zone (Fig. 5), by the montane spruce-silver fir-beech zone (silver fir not shown), and ends with beech forests typical of low elevations (Fig. 7). A characteristic difference with the FORECE model is that the gradients are smoother. FORECE does not produce a transition from beech to oak-beech forests (cf. Fig. 2), and both FORECE and FORCLIM fail to simulate the transition to insubrian oak-chestnut forests at high temperatures. (The insubrian climate is characteristic of the southern edge of the European Alps. Temperatures are close to those of the Mediterranean area, but the annual precipitation sum is much higher. However the temporal distribution of precipitation typically leads to prolonged drought periods in summer [cf. Ellenberg 1986].)

3. Model response to drought gradient.-As noted above, both FORECE and FORCLIM encounter difficulties when simulating the ecotones along drought gradients. FORECE predicts the occurrence of strong droughts that lead to the abrupt decline of Picea excelsa (Fig. 5) and F. silvatica (Fig. 7) at low and high temperatures, respectively. These species give way to transition forests that are dominated by Acer pseudoplatanus and, at higher temperatures, by Abies alba. When drought increases further, oak-chestnut and oak-pine stands are simulated. While ForCLIM-E/P does not simulate the dominance of $A$. pseudoplatanus at low temperatures, the transition forests are dominated entirely by $A$. alba and are replaced by oak-chestnut and oak-pine stands as precipitation decreases further. FORCLIM-E/P/S yields a direct transition from beech 

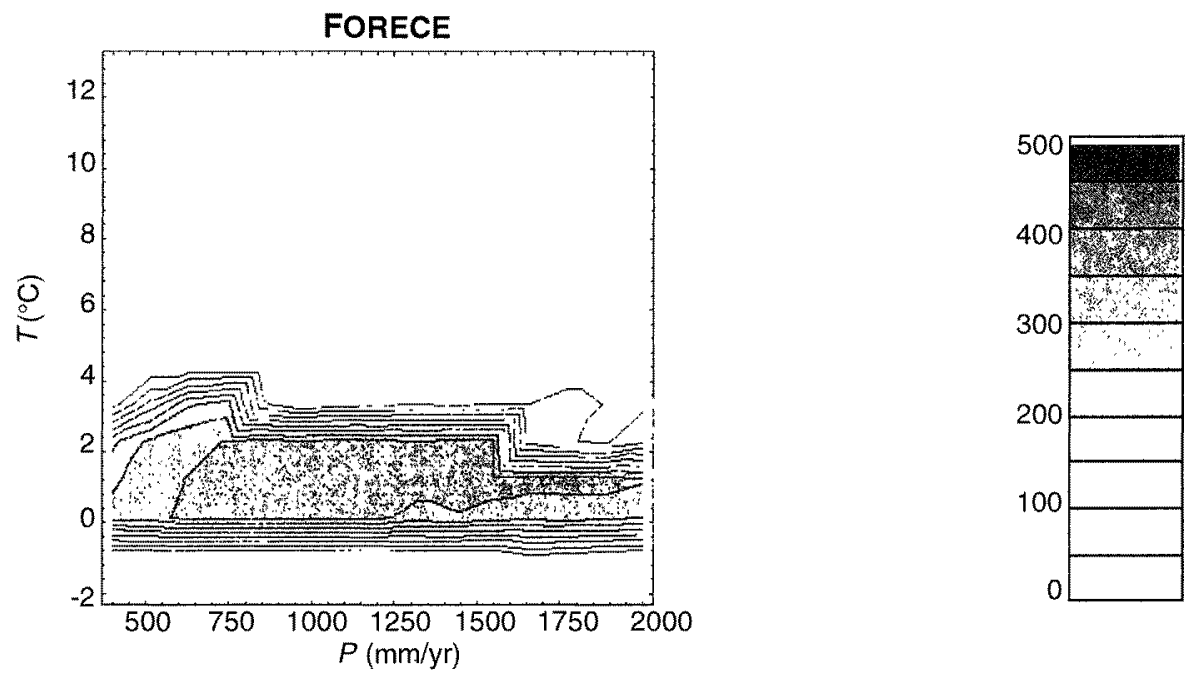

\section{FOR CLIM-E/P}

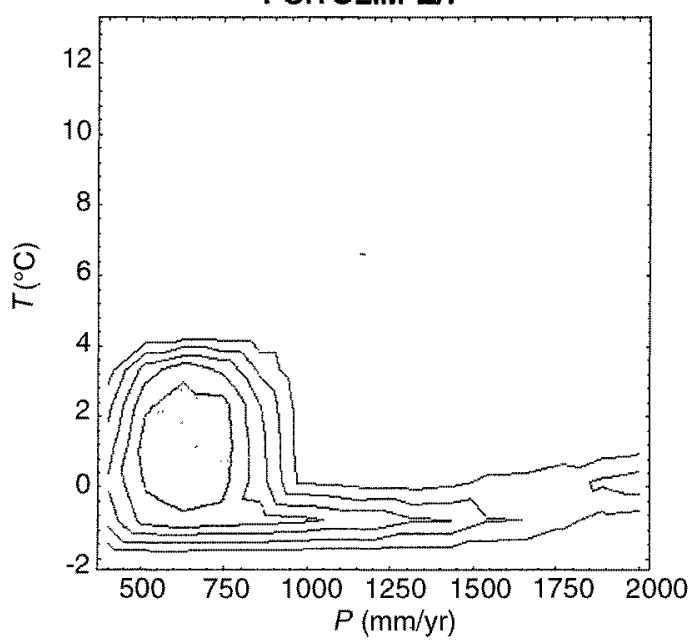

FOR CLIM-E/P/S

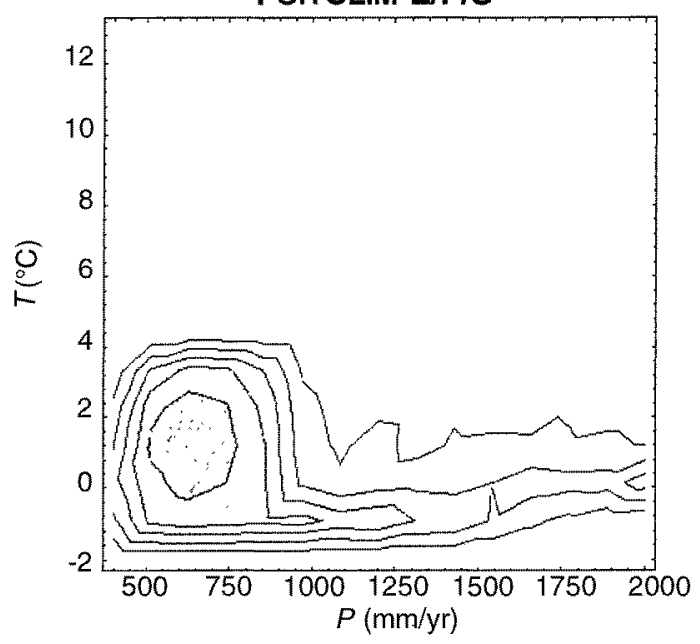

FIG. 6. Contour plot of Pinus cembra biomass ( $\mathrm{t} / \mathrm{ha}$ ) as simulated by FORECE (top), ForCLIM-E/P (bottom left), and FORCLIM-E/P/S (bottom right).

to oak forests above $T=7^{\circ} \mathrm{C}$, which may be realistic (Fig. 3); A. alba comes to dominance only in the area centered around $6^{\circ} \mathrm{C}$ and $700 \mathrm{~mm} / \mathrm{yr}$.

\section{Discussion}

\section{Model verification}

Site Bever. - The landscape around the subalpine, continental site Bever is characterized by forests dominated by Norway spruce (Picea excelsa) on moist north-facing slopes (Larici-Piceetum, Ellenberg and Klötzli 1972), whereas south-facing slopes typically are covered by the Larici-Pinetum cembrae where European larch (Larix decidua) dominates in the early phase and Swiss Stone pine (Pinus cembra) in the late successional phase (Ellenberg 1986). Ellenberg and Klötzli (1972:738) note that Pinus montana arborea and $P$. excelsa are locally dominant in this type of community.
FORECE lacks a differentiation between sites of different slope and aspect, but its results are still characteristic of the forest composition found on southfacing slopes at Bever, although the lack to grow any $P$. excelsa may constitute a deficiency (Fig. 2). The simulation with ForCLIM-E/P for a south-facing slope at Bever (Fig. 2) yields the same overall characteristics as FORECE. Since $P$. montana arborea is not included in the forest models, the presence of the ecologically closely related species Pinus silvestris in ForCLIM appears plausible. The low biomass of $P$. excelsa in FORCLIM-E/P corresponds to phytosociological descriptions. The larch-spruce forest simulated by FORCLIM-E/P for north-facing slopes at Bever is also quite realistic and corresponds to the pattern observed in the landscape.

Site Davos. - The site Davos is characterized by spruce forests (Larici-Piceetum, Ellenberg and Klötzli 1972:736), where the early successional phase is dom- 

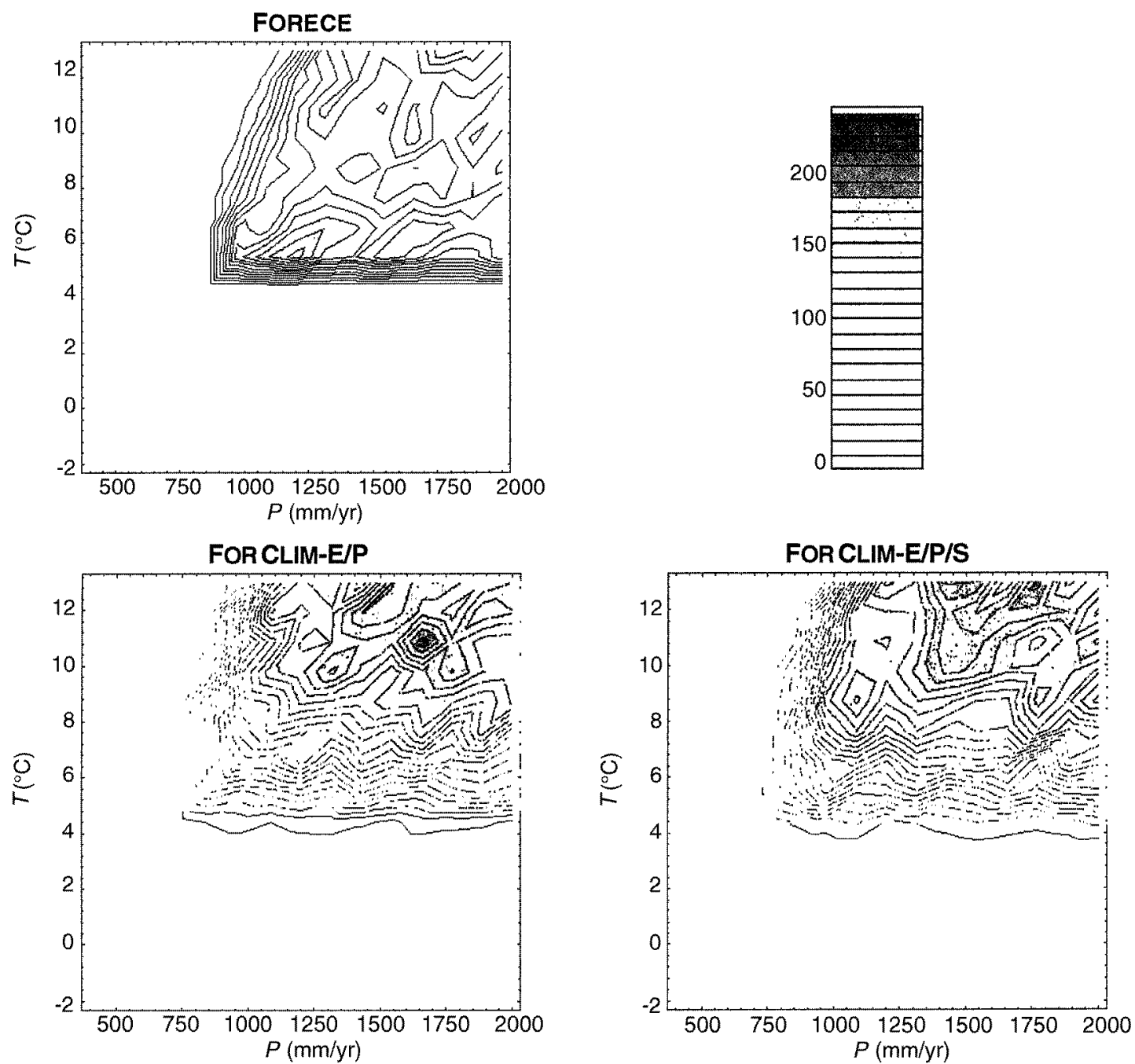

FIG. 7. Contour plot of Fagus silvatica biomass (t/ha) as simulated by FORECE (top), ForCLIM-E/P (bottom left), and ForCLIM-E/P/S (bottom right).

inated by $L$. decidua followed by $P$. excelsa. $P$. cembra may be locally dominant, and in closely related communities Abies alba is also present locally (Ellenberg and Klötzli 1972).

The overall forest characteristics simulated by the models correspond fairly well to these descriptions. The presence of $A$. alba in ForCLIM-E/P appears plausible (Ellenberg and Klötzli 1972), but the presence of $P$. nigra most certainly is a model anomaly. $P$. nigra is typical of open, moist sites (Hess et al. 1980) that occur in few places in the Davos area.

The moderate increase of the aboveground biomass as compared to Bever is quite realistic; both Bever and Davos are subalpine sites where temperature strongly limits tree growth (Ellenberg 1986).

Site Bern.-At low elevations (e.g., site Bern), a variety of communities dominated primarily by European beech (Fagus silvatica) and, in drier places, by oak species (Quercus spp.) is characteristic of the landscape
(Ellenberg and Klötzli 1972, Ellenberg 1986). Many other deciduous species occur in these forests, such as maple (Acer spp.), ash (Fraxinus excelsior), and elm (Ulmus scabra), but they all have minor abundance. Coniferous species like $P$. excels $a$ and $A$. alba do not have a dominating role, either.

The dominance of $F$. silvatica in both models corresponds to these expectations, whereas the large abundance of $A$. alba probably is an anomaly that is due to its large maximum height and the formulation of asymmetric competition for light, as discussed by Kienast and Kuhn (1989b). The strong abundance in FORECE of Acer, especially $A$. platanoides, and of $T$. platyphyllos most likely are anomalies, too.

While the abundance of Quercus spp. in the early successional phase in ForCLIM may be exaggerated, its complete absence in FORECE certainly is unrealistic (Ellenberg and Klötzli 1972). The presence of oak in ForCLIM is due to two factors: (1) the use of a new 
growth equation (Eq. 1), and (2) the re-estimation of the species-specific model parameters. Sensitivity studies showed that neither change alone could bring about the presence of Quercus spp. in FORCLIM, which corroborates the use of Eq. 1 to predict maximum tree growth.

It is likely that the maximum of some $250 \mathrm{t} / \mathrm{ha}$ of aboveground biomass that is obtained from FORECE at rich low-elevation sites such as Bern is too low, as evidenced by both yield table data (e.g., Schober 1987) and records from virgin forests (e.g., Leibundgut 1993). The amount of aboveground biomass simulated by FORCLIM appears to be more plausible, but it still requires quantitative testing.

Based on the simulated forest succession at the sites Bever, Davos, and Bern as well as at the other test sites in the European Alps, it is impossible to favor one of the two forest models over the other. At some sites both models yield very similar species compositions (e.g., Bever), at some sites FORCLIM shows slight anomalies (e.g., Davos), whereas at other sites the results from FORECE are less plausible (e.g., Bern). Therefore, I conclude that using forest models at scattered sites along climate gradients is not sufficient to test their applicability along such gradients, and more systematic methods are required.

\section{Model validation}

Aboveground carbon storage.-The pattern of aboveground biomass simulated by FORECE, especially the maximum in the immediate vicinity of the alpine timberline, certainly is not realistic (Fig. 4), whereas the results from both FORCLIM variants are more plausible. For the FORECE simulation, it was assumed that the parameter prescribing the maximum aboveground biomass (SOILQ) is constant throughout the $(T, P)$ space, and this may be unrealistic. However, it should be noted that nitrogen availability ( $\mathrm{uAvN}$ ) was introduced in FORCLIM as a substitute of SOILQ, and for ForCLIM-E/P it was also assumed that $\mathrm{uAvN}$ is constant throughout the climate space (cf. Fig. 1); however, neither of the FORCLIM models produces the anomaly evident with FORECE (Fig. 4).

Realized niches of dominating species.-The phytosociological scheme (Fig. 3) clearly suggests that $P$. excelsa should extend to the alpine timberline in moist areas, a pattern that is recovered by FORCLIM only. Similarly, the smoother decrease of $P$. excelsa towards higher temperatures in FORCLIM appears to be more plausible than the sharp decline simulated by FORECE, although this cannot be inferred from Fig. 3 .

Both FORECE and FORCLIM run into difficulties in the area centered around $T=6^{\circ} \mathrm{C}$ and $P=700 \mathrm{~mm} / \mathrm{yr}$, where $P$. excelsa (and Pinus silvestris) should dominate; the models simulate the occurrence of strong droughts, which exclude $P$. excelsa. This appears to be unrealistic (Fig. 3), suggesting that the response to drought in all three models needs to be improved.
Phytosociological (e.g., Ellenberg 1986) and paleoecological (e.g., Renner 1982) evidence as well as the current distribution and abundance of $P$. cembra suggest that this species dominates in the continental portion of the subalpine zone in the Alps only, a pattern that FORECE does not capture. On the other hand, ForClim suggests that $P$. cembra is codominant close to the alpine timberline in the other areas (Fig. 6), a pattern that is supported, e.g., by Renner (1982).

The abrupt decline of $F$. silvatica simulated by FORECE at $T \approx 5^{\circ} \mathrm{C}$ is located in the middle of the upper montane beech-silver fir zone (Fig. 3); hence this simulated distribution limit certainly is unrealistic. On the other hand, in FORCLIM the species is present down to $\approx 4^{\circ} \mathrm{C}$, i.e., where the transition between montane and subalpine forests occurs (Fig. 3). Neither FORECE nor FORCLIM are capable of simulating the drought-induced transition from beech forests to insubrian and mediterranean forests dominated by oak (Quercus spp.) and chestnut (Castanea sativa), which should occur at $T \approx 10^{\circ} \mathrm{C}$ (Fig. 3 ). In both models, $F$. silvatica remains the most abundant species (Fig. 7). In ForCLIM, Quercus spp. (cf. Fig. 2) are present as well, but they do not attain the abundance hypothesized by Rehder (1965) and Ellenberg (1986). The insubrian climate is characterized by an uneven temporal distribution of precipitation, especially in the summer months (SMA 1901-1990). Consequently, strong droughts occur, although the monthly precipitation sum may be quite high. Both FORECE and FORCLIM-E do not capture these characteristics since they operate on the monthly precipitation sum only. It is likely that the number of rain days per month would have to be introduced into the models to improve model performance.

Ecotones.-1. Location of the timberlines.-All three models agree that the dry timberline roughly follows a straight line in the $(T, P)$ space, extending from the point $\left[13^{\circ} \mathrm{C}, 700 \mathrm{~mm} / \mathrm{yr}\right]$ down to about $\left[5^{\circ} \mathrm{C}, 400\right.$ $\mathrm{mm} / \mathrm{yr}$ ] (Fig. 4), which appears to be plausible. Unfortunately, neither Rehder (1965) nor Ellenberg (1986) included the location of this timberline in their hypothesis, but the location of the alpine timberline can be compared to the simulation results. In FORECE, the simulated alpine timberline does not correspond well to the one hypothesized by Rehder (1965) and Ellenberg (1986), whereas both FORCLIM models capture the fact that the alpine timberline is found at lower temperatures in continental (dry) climates than in maritime (wet) climates.

2. Model response to temperature gradient.-The fact that FORECE simulates the right sequence of species along the temperature gradient but is incapable of predicting the location of the ecotones (Fig. 3) may be due to both the structure of the model and the way it was calibrated. FORECE was developed for predicting forest succession at a number of sites under current climate. Therefore the formulations included in the model did not have to be applicable along climate gra- 
dients; for example, the static "temperature indicator concept" (Ellenberg 1986) introduced unrealistic threshold effects in FORECE. Additionally, the calibration of FORECE did not have to be valid over a large range of continuously varying climatic conditions. Conversely, ForCLIM was constructed and calibrated with the specific objective of simulating forest composition along climate gradients (Bugmann 1994, Fischlin et al. 1995).

3. Model response to drought gradient.-The ecological response to drought gradients simulated by all three models are questionable at best (Ellenberg and Klötzli 1972, Ellenberg 1986), although the oak-chestnut and oak-pine forests simulated in the immediate vicinity of the dry timberline appear to be plausible. Comparative simulation experiments performed with the models FORECE, FORSKA (Prentice et al. 1993), and FORCLIM along drought gradients in the landscape of eastern Germany suggest that each model fails in different ways (e.g., Lasch and Lindner 1995, Lindner et al., in press). The models yielded vast differences concerning, for example, the simulated evapotranspiration and drought stress and, consequently, also the species composition. This constitutes a severe problem for the application of these models under conditions of climatic change, because increasing temperature combined with stable or decreasing precipitation, i.e., increasing drought, is a likely scenario for many regions of the world (e.g., Houghton et al. 1992).

It is likely that not a single factor, but a number of causes are involved in the poor model performance along drought gradients: (1) the parameters denoting the drought tolerance of the tree species may have been estimated erroneously; (2) the simple "bucket" model of soil water balance is not capable of tracking soil moisture content under warm/dry conditions; (3) the feedbacks between vegetation properties (e.g., leaf area index) and soil water balance (e.g., evapotranspiration) that have been neglected in the model formulation may become important under these conditions (cf. Fig. 1); and (4) neither the "dry days" approach (FORECE) nor the evapotranspiration deficit approach (FORCLIM, Eq. 6) are appropriate indices for expressing drought as experienced by trees. It is currently impossible to say which of these factors is most important, but if we are to increase the reliability of gap models for simulating species composition along drought gradients, it will be necessary to perform rigorous sensitivity analyses as well as quantitative comparisons of different soil moisture submodels.

\section{Model structure of FORCLIM}

FORCLIM was designed to be as similar as possible to the predecessor model, FORECE, although for some of the formulations there are more recent approaches in the literature. For example, it is known that the upper limit for the degree-day response of tree growth as incorporated in FORCLIM is questionable, and more plausible formulations have been proposed (Bonan and Sirois 1992). Also, there are advanced formulations for modeling crown geometry (Leemans and Prentice 1989) and the stress-induced mortality rate (Prentice et al. 1993). Further improvements of FORCLIM would certainly have to deal with these issues. On the other hand, it is important to recognize that we need to demonstrate that these more recent approaches represent improvements from the point of view of the simulated dynamics (Bugmann and Martin 1995). Otherwise, incorporating more advanced and typically more detailed formulations into the models would be "l'art pour l'art." Unfortunately, there is a glaring lack of quantitative model comparisons in this respect (cf. Bugmann et al., in press $b$ ).

Current gap models parameterize tree recruitment in a very simplistic manner by applying a small number of environmental "filters" to determine the establishment of saplings, not seedlings. In the context of climatic change regeneration dynamics, dispersal and migration may become crucial processes determining a lot of the response of forests. It is unlikely that the current generation of gap models is able to project the outcome of these processes realistically, and a revision of the modeling strategy is likely to be required in this respect.

The modular structure of FORCLIM permitted evaluation of the importance of explicitly simulating carbon and nitrogen turnover in the soil (ForCLIM-S) in addition to the conventional set-up of forest gap models (FORCLIM-E/P). The simulation experiments in the climate space yielded slight quantitative differences between ForCLIM-E/P and ForCLIM-E/P/S (e.g., simulated total aboveground biomass, Fig. 4; abundance of some species, Fig. 5), but the qualitative behavior is quite similar (e.g., the realized niches of the species, Figs. 5-7). Since the simulation study was designed to represent average soils across the climate space, this suggests that for these conditions the addition of a submodel treating soil carbon/nitrogen dynamics adds little to the qualitative model behavior. This may explain why the majority of forest gap models developed so far have been remarkably successful, although they have ignored belowground dynamics (e.g., Botkin et al. 1972, Shugart 1984, Solomon 1986, Botkin 1993).

\section{Conclusions}

\section{Simplification of current forest gap models}

In the present study, a rather complex forest gap model for European conditions (FORECE, Kienast 1987 ) with a parameter space of $>1000$ parameters was used as a template to derive a simpler model (FoRCLIM) that has less than half as many parameters and is based on only four factors to predict tree growth, four factors to determine sapling establishment, and two factors to model tree mortality. The simulation results obtained from FORCLIM at the test sites for which FORECE had 
been developed are quite similar to those of FORECE and, in some instances, even more plausible. Hence, some of the factors that had been introduced when developing FORECE contribute little to the behavior of the model, but they may have reduced its generality without conveying clear advantages; the synecological "temperature indicator concept" (Ellenberg 1986) may serve as an example.

The formulation of the factors remaining in FORCLIM was improved from an ecological and a climatological point of view so that the model yields more reliable results when applied along climate and particularly temperature gradients (Bugmann 1994, Fischlin et al. 1995). The combination of model simplification and scrutinization of the remaining factors resulted in plausible species compositions and ecotones in a large fraction of a climate space spanned by the annual mean temperature and the annual precipitation sum, whereas the FORECE model exhibited many unrealistic thresholds. Although the present version of FORCLIM also showed a number of unrealistic features, especially along drought gradients, the improved performance of FORCLIM vs. FORECE suggests that complexity per se does not necessarily increase the realism or the precision of an ecological model (cf. Bonan 1993, Bugmann and Martin 1995).

Some of the current forest gap models can be simplified without reducing the realism of their behavior, and models other than FORECE should be scrutinized in this respect as well (cf. Fulton 1991). Although it is possible that simpler models could miss processes that are important in the real world, they would be advantageous for various reasons. First, the estimation of a large number of parameters is subject to considerable uncertainty because of a lack of data. Simpler models require fewer parameters to be estimated, hence the uncertainty inherent in the models will decrease. Second, model properties should always be studied in detail before model application; since simpler models are easier to run, they are also more easily amenable to a detailed analysis. Finally, complex models often have to be treated as "black boxes," i.e., it is difficult to derive how a particular model behavior was brought about; conversely, the behavior of a simple model is easier to understand.

\section{Forest gap models and climate gradients}

The evaluation of model behavior at scattered sites along an ecological gradient, which has become a standard practice in studies using forest gap models (e.g., Solomon 1986, Kienast 1991) appears to be necessary, but insufficient to show their validity for simulating forest dynamics along such gradients. The present study shows that two gap models (FORECE and FORCLIM) may behave very similarly at a large number of sites in the European Alps (Fig. 2), and based on these data alone one could not favor one of the models with respect to its applicability to study the species composition along climate gradients.

However, when the two models are used to simulate the species composition systematically in a climate space spanned by the annual mean temperature and the annual precipitation sum, i.e., along continuous climate gradients, their behavior diverges strongly. The present study suggests that some forest models, e.g., FORECE, have been tuned to yield a plausible species composition and aboveground biomass at selected locations in the climate space, but that they are not apt for simulating species composition along gradients of continually changing climatic conditions. This inability casts serious doubts on the reliability of previous assessments of the impacts of climatic change performed with gap models. These models need to be scrutinized carefully, and model testing must be based on methods other than the site-oriented approach used to date. The evaluation of the simulated species composition in a climate space as presented in this paper is an example of how to deal with these issues, but further studies are required, especially on the dynamic behavior of the models in a changing climate. A major problem in this context is the lack of field data at adequate temporal (several centuries) and spatial (several hectares) scales (e.g., Shugart 1984). One of the few data sources in this respect is the pollen record (cf. Solomon et al. 1980, Solomon and Tharp 1985, Lotter and Kienast 1992).

\section{The importance of model comparisons}

Model validation is a crucial issue if models are to predict the future behavior of a system. As mentioned above, there is a chronic lack of validation data for long-term processes such as forest succession. Therefore, any efforts that aim at starting or continuing longterm monitoring programs of forests are highly valuable. However, each data source also has strong disadvantages. For example, most monitoring programs have started in the early 20 th century at best, hence they do not yet span a century, which is a short time for forest succession. On the other hand, paleodata like pollen records do not usually provide the required temporal resolution. Moreover, pollen data do not correspond to the output of gap models, and additional assumptions must be made to map simulated speciesspecific biomass data to pollen data. Similarly, the climate space (Fig. 3) used in this study represents a rather fuzzy, qualitative hypothesis on the "dominating species," whereas the gap models produce species-specific biomass quantitatively. Consequently, the comparison of some model output to data often is little convincing and, more importantly, insufficient to judge the hypotheses underlying the model.

This situation can be improved, however, when the behavior of several models is compared with each other as well as with field data. For example, the comparison of FORECE, FORCLIM-E/P, and FORCLIM-E/P/S in the 
climate space (Figs. 3-7) allowed more comprehensive evaluation of the performance of the models. Of course the comparison of various models can never be a substitute for comparisons between models and data, but it can greatly increase the amount of information that can be gathered from the data. If standardized data sets can be provided, rigorous model-model and modeldata comparisons would be very helpful and could improve the quality of forest gap models considerably (cf. Harrison 1995, Bugmann et al., in press $b$ ).

\section{ACKNOWLEDGMENTS}

This study is based on the author's doctoral dissertation submitted to the Swiss Federal Institute of Technology Zurich (ETHZ). The advice by Andreas Fischlin and Hannes Flühler of the Institute of Terrestrial Ecology ETHZ as well as the financial support of ETHZ are gratefully acknowledged. I also would like to thank Felix Kienast for access to the FORECE model and valuable discussions. Two anonymous reviewers provided many stimulating comments.

\section{Literature Cited}

Aber, J. D., D. B. Botkin, and J. M. Melillo. 1979. Predicting the effects of different harvesting regimes on productivity and yield in northern hardwoods. Canadian Journal of Forest Research 9:10-14.

Aber, J. D., and J. M. Melillo. 1982. FORTNITE: a computer model of organic matter and nitrogen dynamics in forest ecosystems. University of Wisconsin Research Bulletin R3130.

Alexander, M. 1977. Introduction to soil microbiology. John Wiley, New York, New York, USA.

Allen, J. C. 1976. A modified sine wave method for calculating degree days. Environmental Entomology 5:388-396.

Bantle, H. 1989. Programmdokumentation Klima-Datenbank am RZ-ETH Zürich. Swiss Meteorological Agency, Zürich, Switzerland.

Bassett, J. R. 1964. Tree growth as affected by soil moisture availability. Soil Science Proceedings 28:436-438.

Berg, B., and H. Staaf. 1981. Leaching, accumulation and release of nitrogen in decomposing forest litter. Pages 163178 in F. E. Clark and T. Rosswall, editors. Terrestrial nitrogen cycles: processes, ecosystem strategies and management impacts. Ecological Bulletin (Stockholm) 33.

Bonan, G. B. 1993. Do biophysics and physiology matter in ecosystem models? Climatic Change 24:281-285.

Bonan, G. B., and L. Sirois. 1992. Air temperature, tree growth, and the northern and southern range limits to Picea mariana. Journal of Vegetation Science 3:495-506.

Bonan, G. B., and K. van Cleve. 1992. Soil temperature, nitrogen mineralization, and carbon source-sink relationships in boreal forests. Canadian Journal of Forest Research 22:629-639.

Bormann, F. H., and G. E. Likens. 1979. Pattern and process in a forested ecosystem. Springer, New York, New York, USA.

Botkin, D. B. 1993. Forest dynamics: an ecological model. Oxford University Press, Oxford, England.

Botkin, D. B., J. F. Janak, and J. R. Wallis. 1972. Some ecological consequences of a computer model of forest growth. Journal of Ecology 60:849-872.

Bugmann, H. 1994. On the ecology of mountainous forests in a changing climate: a simulation study. Ph.D. dissertation number 10638. Swiss Federal Institute of Technology, Zurich, Switzerland.

Bugmann, H., and A. Fischlin. 1992. Ecological processes in forest gap models-analysis and improvement. Pages 953-954 in A. Teller, P. Mathy, and J. N. R. Jeffers, editors.
Responses of forest ecosystems to environmental changes. Elsevier Applied Science, London, England.

Bugmann, H., and A. Fischlin. 1994. Comparing the behaviour of mountainous forest succession models in a changing climate. Pages 204-219 in M. Beniston, editor. Mountain environments in changing climates. Routledge, London, England.

Bugmann, H., A. Fischlin, and F. Kienast. In press $a$. Model convergence and state variable update in forest gap models. Ecological Modelling.

Bugmann, H., and Ph. Martin. 1995. How physics and biology matter in forest gap models. Climatic Change 29: 251-257.

Bugmann, H. K. M., Yan Xiaodong, M. T. Sykes, Ph. Martin, M. Lindner, P. V. Desanker, and S. G. Cumming. In press $b$. A comparison of forest gap models: model structure and behaviour. Climatic Change.

Burger, H. 1945, 1947, 1948, 1950, 1951, 1952, 1953. Holz, Blattmenge und Zuwachs. Mitteilungen der Schweizerischen Anstalt für das forstliche Versuchswesen 24:7-103, 25:211-279, 25:435-493, 26:419-468, 26:583-634, 27: 247-286, 28:109-156, 29:38-130.

Clements, F. E. 1936. Nature and structure of the climax. Journal of Ecology 24:252-284.

Coffin, D. P., and W. K. Lauenroth. 1990. A gap dynamics simulation model of succession in a semiarid grassland. Ecological Modelling 49:229-236.

Cole, D. W., and M. Rapp. 1981. Elemental cycling in forest ecosystems. Pages 341-410 in D. E. Reichle, editor. Dynamic properties of forest ecosystems. International Biological Program Publication Number 23, Cambridge University Press, Cambridge, England.

Doyle, T. W. 1981. The role of disturbance in the gap dynamics of a montane rain forest: an application of a tropical forest succession model. Pages 56-73 in D. C. West, H. H. Shugart, and D. B. Botkin, editors. Forest succession: concepts and application, Springer, New York, New York, USA.

Ellenberg, H. 1986. Vegetation Mitteleuropas mit den Alpen in ökologischer Sicht. Verlag Eugen Ulmer, Stuttgart, Germany.

Ellenberg, H., and F. Klötzli. 1972. Waldgesellschaften und Waldstandorte der Schweiz. Mitteilungen der Schweizerischen Anstalt für das forstliche Versuchswesen, Mitteilungen 48:587-930.

Fischlin, A. 1991. Interactive modeling and simulation of environmental systems on workstations. Pages 131-145 in D. P. F. Möller, editor. Proceedings of the Fourth Ebernburger Working Conference on the analysis of dynamic systems in medicine, biology, and ecology. InformatikFachberichte 275. Springer, Berlin, Germany.

Fischlin, A., H. Bugmann, and D. Gyalistras. 1995. Sensitivity of a forest ecosystem model to climate parameterization schemes. Environmental Pollution 87:267-282.

Fischlin, A., D. Gyalistras, O. Roth, M. Ulrich, J. Thöny, T. Nemecek, H. Bugmann, and F. Thommen. 1994. ModelWorks 2.2: an interactive simulation environment for personal computers and workstations. Internal Report Number 14, Systems Ecology Group, Swiss Federal Institute of Technology Zürich, Switzerland.

Fischlin, A., M. A. Mansour, M. Rimvall, and W. Schaufelberger. 1987. Simulation and computer aided control system design in engineering education. Pages 51-60 in I. Troch, P. Kopacek, and F. Breitenecker, editors. Simulation of control systems. Pergamon, Oxford, England.

Fliri, F. 1974. Niederschlag und Lufttemperatur im Alpenraum. Wissenschaftliche Alpenvereinshefte 24.

Friend, A. D., H. H. Shugart, and S. W. Running. 1993. A physiology-based gap model of forest dynamics. Ecology 74:792-797. 
Fulton, M. 1991. A computationally efficient forest succession model: design and initial tests. Forest Ecology and Management 42:23-34.

Gleason, H. A. 1939. The individualistic concept of the plant association. American Midland Naturalist 21:92-110.

Harrison, G. W. 1995. Comparing predator-prey models to Luckinbill's experiment with Didinium and Paramecium. Ecology 76:357-374.

Hess, H. E., E. Landolt, and R. Hirzel. 1980. Flora der Schweiz. Second edition. Birkhäuser, Basel, Switzerland.

Houghton, J. T., B. A. Callander, and S. K. Varney, editors. 1992. Climate change 1992 - the supplementary report to the IPCC scientific assessment. Report prepared for IPCC by Working Group 1. Cambridge University Press, Cambridge, England.

Keane, R. E., S. F. Arno, J. K. Brown, and D. F. Tomback. 1990. Modelling stand dynamics in whitebark pine (Pinus albicaulis) forests. Ecological Modelling 51:73-95.

Kellomäki, S., and H. Väisänen. 1991. Application of a gap model for the simulation of forest ground vegetation in boreal conditions. Forest Ecology and Management 42:3547.

Ker, J. W., and J. H. G. Smith. 1955. Advantages of the parabolic expression of height-diameter relationships. Forestry Chronicle 31:235-246.

Kercher, J. R., and M. C. Axelrod. 1984. Analysis of SILVA a model for forecasting the effects of $\mathrm{SO}_{2}$ pollution and fire on western coniferous forests. Ecological Modelling 23:165-184.

Kienast, F. 1987. FORECE-a forest succession model for southern central Europe. Oak Ridge National Laboratory, Oak Ridge, Tennessee, ORNL/TM-10575.

- 1991. Simulated effects of increasing $\mathrm{CO}_{2}$ on the successional characteristics of Alpine forest ecosystems. Landscape Ecology 5:225-238.

Kienast, F., and N. Kuhn. 1989a. Computergestützte Simulation von Waldentwicklungen. Schweizerische Zeitschrift für das Forstwesen 140:189-201.

Kienast, F., and N. Kuhn. 1989b. Simulating forest succession along ecological gradients in southern Central Europe. Vegetatio 79:7-20.

Lasch, P., and M. Lindner. 1995. Application of two forest succession models at sites in Northeast Germany. Journal of Biogeography 22:485-492.

Leemans, R., and I. C. Prentice. 1989. FORSKA, a general forest succession model. Institute of Ecological Botany, Uppsala, Sweden.

Leibundgut, H. 1993. Europäische Urwälder-Wegweiser zur naturnahen Waldwirtschaft. Haupt, Bern, Switzerland

Lindner, M., H. Bugmann, W. Cramer, and P. Lasch. In press. Impact of climate change on forests: Application of forest succession models across central and eastern Europe. Special Publication of the Forestry and Game Management Research Institute, Jiloviste, Czech Republic, in press. Proceedings of a IUFRO workshop, Prague, October 1994.

Lotter, A., and F. Kienast. 1992. Validation of a forest succession model by means of annually laminated sediments. Pages 25-31 in M. Saarnisto and A. Kahra, editors. Proceedings of the INQUA workshop on laminated sediments, 4-6 June, 1990, Lammi, Finland. Geological Survey of Finland, Special Paper Series 14.

Lyr, H., H.-J. Fiedler, and W. Tranquillini, editors. 1992. Physiologie und Ökologie der Gehölze. Fischer, Jena, Germany.

Martin, Ph. 1992. EXE: a climatically sensitive model to study climate change and $\mathrm{CO}_{2}$ enrichment effects on forests. Australian Journal of Botany 40:717-735.

Meentemeyer, V. 1978. Macroclimate and lignin control of litter decomposition rates. Ecology 59:465-472.

Meentemeyer, V., J. Gardner, and E. O. Box. 1985. World patterns and amounts of detrital soil carbon. Earth Surface Processes and Landforms 10:557-567.

Melillo, J. M., J. D. Aber, and J. F. Muratore. 1982. Nitrogen and lignin control of hardwood leaf litter decomposition dynamics. Ecology 63:621-626.

Mintz, Y., and Y. V. Serafini. 1992. A global monthly climatology of soil moisture and water balance. Climate Dynamics 8: 13-27.

Moore, A. D. 1989. On the maximum growth equation used in forest gap simulation models. Ecological Modelling 45: 63-67.

Müller, M. J. 1982. Selected climatic data for a global set of standard stations for vegetation science. Tasks for vegetation science. Junk, The Hague, The Netherlands.

O'Brien, S. T., B. P. Hayden, and H. H. Shugart. 1992. Global climatic change, hurricanes, and a tropical forest. Climatic Change 22:175-190.

Pastor, J., J. D. Aber, and C. A. McClaugherty. 1984. Aboveground production and $\mathrm{P}$ cycling along a nitrogen mineralization gradient on Blackhawk Island, Wisconsin. Ecology 65:256-268.

Pastor, J., and R. J. Naiman. 1992. Selective foraging and ecosystem processes in boreal forests. American Naturalist 139:690-705.

Pastor, J., and W. M. Post. 1985. Development of a linked forest productivity-soil process model. United States Department of Energy ORNL/TM-9519.

Pastor, J., and W. M. Post. 1986. Influence of climate, soil moisture, and succession on forest carbon and nitrogen cycles. Biogeochemistry 2:3-27.

Pastor, J., and W. M. Post. 1988. Response of northern forests to $\mathrm{CO}_{2}$-induced climate change. Nature 334:55-58.

Post, W. M., T.-H. Peng, W. R. Emanuel, A. W. King, V. H. Dale, and D. L. DeAngelis. 1990. The global carbon cycle. American Scientist 78:310-326.

Prentice, I. C., W. Cramer, S. P. Harrison, R. Leemans, R. A. Monserud, and A. M. Solomon. 1992. A global biome model based on plant physiology and dominance, soil properties and climate. Journal of Biogeography 19:117-134.

Prentice, I. C., M. T. Sykes, and W. Cramer. 1991. The possible dynamic response of northern forests to global warming. Global Ecology and Biogeography Letters 1:129-135.

Prentice, I. C., M. T. Sykes, and W. Cramer. 1993. A simulation model for the transient effects of climate change on forest landscapes. Ecological Modelling 65:51-70.

Rehder, H. 1965. Die Klimatypen der Alpenkarte im Klimadiagramm-Weltatlas (Walther and Lieth) und ihre Beziehungen zur Vegetation. Flora B 156:78-93.

Renner, F. 1982. Beiträge zur Gletschergeschichte des Gotthardgebietes und dendroklimatologische Analysen an fossilen Hölzern. In G. Furrer, W. A. Keller, M. Gamper, and J. Suter, editors. Physische Geographie 8. Geographisches Institut, Universität Zürich, Zürich, Switzerland.

Running, S. W., R. R. Nemani, and R. D. Hungerford. 1987. Extrapolation of synoptic meteorological data in mountainous terrain and its use for simulating forest evapotranspiration and photosynthesis. Canadian Journal of Forest Research 17:472-483.

Schober, R. 1987. Ertragstafeln wichtiger Baumarten bei verschiedener Durchforstung. Sauerländer, Frankfurt, Germany.

Shugart, H. H. 1984. A theory of forest dynamics: the ecological implications of forest succession models. Springer, New York, New York, USA.

Shugart, H. H., and W. R. Emanuel. 1985. Carbon dioxide increase: the implications at the ecosystem level. Plant, Cell and Environment 8:381-386.

Shugart, H. H., R. Leemans, and G. B. Bonan, editors. 1992. A systems analysis of the global boreal forest. Cambridge University Press, Cambridge, England. 
Shugart, H. H., and I. R. Noble. 1981. A computer model of succession and fire response of the high-altitude Eucalyptus forest of the Brindabella Range, Australian Capital Territory. Australian Journal of Ecology 6:149-164.

Shugart, H. H., and D. L. Urban. 1989. Factors affecting the relative abundances of tree species. Pages 249-273 in P. J. Grubb and J. B. Whittaker, editors. Toward a more exact ecology. Thirtieth Symposium of the British Ecological Society. Blackwell, Oxford, England.

Shugart, H. H., and D. C. West. 1977. Development of an Appalachian deciduous forest succession model and its application to assessment of the impact of the chestnut blight. Journal of Environmental Management 5:161-179.

Sirois, L., G. B. Bonan, and H. H. Shugart. 1994. Development of a simulation model of the forest-tundra transition zone of northeastern Canada. Canadian Journal of Forest Research 24:697-706.

SMA (Swiss Meteorological Agency). 1901-1990. Annalen der Schweizerischen Meteorologischen Anstalt. Swiss Meteorological Agency, Zürich, Switzerland.

Solomon, A. M. 1986. Transient response of forests to $\mathrm{CO}_{2}$ induced climate change: simulation modeling experiments in eastern North America. Oecologia 68:567-579.

Solomon, A. M., H. R. Delcourt, D. C. West, and T. J. Blasing. 1980. Testing a simulation model for reconstruction of prehistoric forest-stand dynamics. Quaternary Research 14: 275-293.

Solomon, A. M., and M. L. Tharp. 1985. Simulation experiments with late quaternary carbon storage in mid-latitude forest communities. Pages 235-250 in E. T. Sundquist and W. S. Broecker, editors. The carbon cycle and atmospheric $\mathrm{CO}_{2}$ : natural variations archean to present. American Geophysical Union, Geophysical Monograph 32.

Swartzman, G. L., and S. P. Kaluzny. 1987. Ecological simulation primer. Macmillan, New York, New York, USA.

Thöny, J., A. Fischlin, and D. Gyalistras. 1994. RASS: towards bridging the gap between interactive and off-line simulation. Pages 99-103 in J. Halin, W. Karplus, and R. Rimane, editors. Proceedings of the First Joint Conference of International Simulation Societies (CISS). Society for Computer Simulation International, San Diego, California, USA.

Thornthwaite, C. W., and J. R. Mather. 1957. Instructions and tables for computing potential evapotranspiration and the water balance. Publications in Climatology 10:183311.

Waring, R. H., and W. H. Schlesinger. 1985. Forest ecosystems: concepts and management. Academic Press, London, England.

Watt, A. S. 1947. Pattern and process in the plant community. Journal of Ecology 35:1-22.

Wirth, N. 1985. Programming in Modula-2. Third, corrected edition. Springer-Verlag, Berlin, Germany.

Wirth, N., J. Gutknecht, W. Heiz, H. Schär, H. Seiler, C. Vetterli, and A. Fischlin. 1992. MacMETH-a fast Modula-2 language system for the Apple Macintosh. User Manual, Institut für Informatik ETHZ, 8092 Zürich, Switzerland. 